\title{
An aerosol chamber investigation of the heterogeneous ice nucleating potential of refractory nanoparticles
}

\author{
R. W. Saunders ${ }^{1}$, O. Möhler ${ }^{2}$, M. Schnaiter ${ }^{2}$, S. Benz ${ }^{2}$, R. Wagner ${ }^{2}$, H. Saathoff ${ }^{2}$, P. J. Connolly ${ }^{3}$, R. Burgess ${ }^{3}$, \\ B. J. Murray ${ }^{1}$, M. Gallagher ${ }^{3}$, R. Wills ${ }^{1}$, and J. M. C. Plane ${ }^{1}$ \\ ${ }^{1}$ School of Chemistry, University of Leeds, Woodhouse Lane, Leeds LS2 9JT, UK \\ ${ }^{2}$ Institute for Meteorology and Climate Research, Karlsruhe Institute of Technology (KIT), 76021 Karlsruhe, Germany \\ ${ }^{3}$ School of Earth, Atmospheric and Environmental Sciences, The University of Manchester, Oxford Road, Manchester \\ M13 9PL, UK
}

Received: 18 September 2009 - Published in Atmos. Chem. Phys. Discuss.: 2 November 2009

Revised: 23 January 2010 - Accepted: 30 January 2010 - Published: 4 February 2010

\begin{abstract}
Nanoparticles of iron oxide (crystalline and amorphous), silicon oxide and magnesium oxide were investigated for their propensity to nucleate ice over the temperature range $180-250 \mathrm{~K}$, using the AIDA chamber in Karlsruhe, Germany.

All samples were observed to initiate ice formation via the deposition mode at threshold ice super-saturations ( $\mathrm{RHi}_{\text {thresh }}$ ) ranging from $105 \%$ to $140 \%$ for temperatures below $220 \mathrm{~K}$. Approximately $10 \%$ of amorphous $\mathrm{Fe}_{2} \mathrm{O}_{3}$ particles (modal diameter $=30 \mathrm{~nm}$ ) generated in situ from a photochemical aerosol reactor, led to ice nucleation at $\mathrm{RHi}_{\text {thresh }}=140 \%$ at an initial chamber temperature of $182 \mathrm{~K}$. Quantitative analysis using a singular hypothesis treatment provided a fitted function $\left[n_{s}(190 K)=10^{\left(3.33 \times s_{\text {ice }}\right)+8.16}\right]$ for the variation in ice-active surface site density $\left(n_{s}: \mathrm{m}^{-2}\right)$ with ice saturation ( $\left.s_{\text {ice }}\right)$ for $\mathrm{Fe}_{2} \mathrm{O}_{3}$ nanoparticles. This was implemented in an aerosol-cloud model to determine a predicted deposition (mass accommodation) coefficient for water vapour on ice of 0.1 at temperatures appropriate for the upper atmosphere. Classical nucleation theory was used to determine representative contact angles $(\theta)$ for the different particle compositions. For the in situ generated $\mathrm{Fe}_{2} \mathrm{O}_{3}$ particles, a slight inverse temperature dependence was observed with $\theta=10.5^{\circ}$ at $182 \mathrm{~K}$, decreasing to $9.0^{\circ}$ at $200 \mathrm{~K}$ (compared with $10.2^{\circ}$ and $11.4^{\circ}$ respectively for the $\mathrm{SiO}_{2}$ and $\mathrm{MgO}$ particle samples at the higher temperature).

These observations indicate that such refractory nanoparticles are relatively efficient materials for the nucleation of ice under the conditions studied in the chamber which correspond to cirrus cloud formation in the upper troposphere. The results also show that $\mathrm{Fe}_{2} \mathrm{O}_{3}$ particles do not act as
\end{abstract}

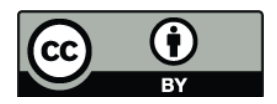

Correspondence to: J. M. C. Plane (j.m.c.plane@leeds.ac.uk) ice nuclei under conditions pertinent for tropospheric mixed phase clouds, which necessarily form above $\sim 233 \mathrm{~K}$. At the lower temperatures $(<150 \mathrm{~K})$ where noctilucent clouds form during summer months in the high latitude mesosphere, higher contact angles would be expected, which may reduce the effectiveness of these particles as ice nuclei in this part of the atmosphere.

\section{Introduction}

Insoluble refractory material, in the form of primary and secondary aerosol, is thought to play a crucial catalytic role in the activation of ice crystal formation in cirrus clouds in the troposphere and in polar stratospheric clouds (PSCs) in the stratosphere (Pruppacher and Klett, 1997; Zondlo et al., 2000). In addition, secondary aerosol, commonly referred to as meteoric smoke, which forms from recondensed material derived from ablating meteoroids in the upper mesosphere, is the favoured candidate for the production of high altitude ice clouds $(83-85 \mathrm{~km})$ which occur at high latitudes during summer, and are known as noctilucent clouds (NLCs) (also termed polar mesospheric clouds or PMCs) (Gadsden and Schroder, 1989; Reid, 1997; Rapp and Thomas, 2006).

Whilst the presence of meteoritic aerosol at lower altitudes has been substantiated through direct sampling from aircraft in the 1960's (Mossop, 1963) and, more recently, via sampling and in situ measurements (Murphy et al., 1998; Cziczo et al., 2001, 2004; Curtius et al., 2005), the existence, although long predicted from theoretical and modelling work (Rosinski and Snow, 1961; Hunten et al., 1980), let alone the participation in ice cloud nucleation, of meteoric smoke in the mesosphere awaits definitive evidence. A series of rocket-borne sampling devices launched in the 1960's did

Published by Copernicus Publications on behalf of the European Geosciences Union. 
recover a variety of particulate samples from the upper atmosphere (Hemenway et al., 1963; Farlow et al., 1970) which showed a range of sizes, morphologies and compositions, although whether any of these samples could be classed as meteoric smoke remains unanswered. However, two groups of collected particles, labelled "type 2" and "type 5" in the paper of Farlow et al. (1970), did show an aggregated nature and extended morphology, possibly indicative of meteoric smoke. More recently, in situ measurements of positively charged particles at 80-90 km (Rapp et al., 2005) and satellite solar occultation measurements (Hervig et al., 2009) have lent further support to the presence of nano-sized meteoric smoke in the upper atmosphere, whilst line features observed in radar spectra have been shown to be consistent with the effect of charged particles present in the upper atmosphere (Strelnikova et al., 2007).

The classical heterogeneous nucleation theory of Fletcher (1958, 1959, 1969), based upon thermodynamic considerations of ice crystal activation and the role of particle size and surface inhomogeneity i.e. preferential activation sites, is applied primarily to spherical particles of crystalline materials e.g. silver iodide, for which a close "lattice fit" with hexagonal ice $\mathrm{I}_{h}$ was originally proposed as the primary reason for the high activation efficiency of this material. However, this scenario is somewhat idealised and it seems more likely that meteoric smoke particles are porous or "fluffy" aggregates of spherical, 'primary' particles of amorphous material such as iron oxide or silicate (Saunders and Plane, 2006). In addition, the formation of the metastable cubic phase of ice $\mathrm{I}_{c}$ in the Earth's atmosphere (Whalley, 1983) has recently been shown to be likely to occur more readily than previously thought in the lower atmosphere via homogeneous freezing (Murray et al., 2005). It therefore seems likely that in the mesosphere, where temperatures well below $150 \mathrm{~K}$ have been regularly measured at high latitudes in the summer mesopause region (von Zahn and Meyer, 1989; Lübken, 1999), where NLC formation is typically observed, and where significant water supersaturations $(S \gg 1)$ have also been identified (Seele and Hartogh, 1999), ice $I_{c}$ formation through heterogeneous nucleation could occur. On this very point, the study of Roddy (1984) specifically addressed the favourable lattice fits of possible meteoric materials of cubic structure (i.e. $\mathrm{FeO}, \mathrm{MgO}$ ). However, such a consideration alone is insufficient to account for the ice nucleating potential of a material (Evans, 1965), particularly if it is of a non-crystalline nature. Indeed, another possibility is that of amorphous ice formation, which to date has not been observed in the Earth's upper atmosphere but has been shown to be relatively common in other environments such as outer planetary satellites and comets (Baragiola, 2003). In light of these considerations, theoretical predictions of ice particle nucleation and activation based upon the assumption of hexagonal ice formation on crystalline materials are, in the realm of the upper atmosphere, likely to be somewhat erroneous. It is therefore preferable, where possible, to directly measure the ice nucle- ation potential of candidate materials of realistic composition and morphology under conditions approaching those which exist in the atmosphere.

In terms of the heterogeneous ice nucleating potential of meteoric smoke, nothing exists in the current literature regarding the properties of the most likely aerosol species (metal and silicon oxides and metal silicates i.e. olivines) under conditions relevant to the upper atmosphere and at nanoparticle dimensions $(<10 \mathrm{~nm})$, expected to be present at such high altitudes. Whilst deposition nucleation studies, with regard to the lower atmosphere, for materials of terrestrial origin such as mineral dusts (Archuleta et al., 2005; Möhler et al., 2006) and soot (Dymarska et al, 2006; Kärcher et al., 2007) are of great current interest, only the experimental study of Bigg and Giutronich (1967) seems to have considered the activating role of recondensed meteoric material in the atmosphere, and only then with respect to the troposphere. Other attempts to investigate the freezing capacity of meteoritic material, such as that of Biermann et al. (1996) with regard to acid-water solutions in the stratosphere, have reported a largely negative (inactive) potential, but the samples used (whole or ground micrometeorites) are unlikely to be representative of the composition and morphology of recondensed (smoke) particles, and consequently exhibit the appropriate particle surface and nucleation properties. This point was argued by Bigg and Giutronich (1967) with respect to earlier cited nucleation studies.

Although the study of Bigg and Giutronich indicated that low density particle aggregates, formed via the boiling of a chondritic meteorite, required relatively low threshold ice supersaturations at $\sim 263 \mathrm{~K}$, the study of heterogeneous nucleation under the extreme conditions encountered in the mesosphere, obviously presents a much greater experimental challenge.

This was the motivation that led us to conduct a series of low temperature nucleation studies on a variety of commercially available crystalline and amorphous nanopowders of potential meteoric smoke compositions, as well as a laboratory-generated amorphous iron oxide powder, and nanoparticles of the same iron oxide formed in situ using a photochemical aerosol system. The work was conducted at the AIDA (Aerosol Interactions and Dynamics in the Atmosphere) chamber in Karlsruhe, Germany. This is an $84.3 \mathrm{~m}^{3}$ aluminium chamber in which temperatures down to $\sim 183 \mathrm{~K}$ and pressures less than $1 \mathrm{~Pa}$ can be attained for the investigation of the deposition mode ice nucleation of aerosol particles injected into the chamber volume (Möhler et al., 2006; Field et al., 2006; Cotton et al., 2007). The facility at the Karlsruhe Institute of Technology (KIT) includes a suite of analytical techniques for the in situ or on line monitoring of particle size distribution, ice crystal growth and light scattering along with continual monitoring of the ambient pressure, temperature and supersaturation levels with respect to both water and ice in the chamber, throughout the course of an experimental run. 
Our primary aim in these experiments was to identify the critical threshold conditions of temperature and ice supersatuation under which heterogeneous ice nucleation is activated by the particle samples described and, if possible, to extend the analysis, via modelling, to include a derivation of ice formation rates in order to establish the likely role of such materials as ice nuclei (IN) in the lower, middle and upper atmosphere, with regard to their proposed participation in cirrus, polar stratospheric and noctilucent cloud formation.

\section{Meteoric Smoke Particles (MSPs) and their experi- mental analogues}

The compositions of the various particle samples were chosen to most closely reflect those thought to comprise meteoric smoke. These nanoparticles are formed in the upper mesosphere by the condensation of predominantly $\mathrm{Fe}, \mathrm{Mg}$ and Si oxides (+ mixed silicates i.e. olivine minerals). The metal and silicon atoms are deposited in the atmosphere as a result of the ablation or frictional heating of meteors as they pass through the Earth's upper atmosphere (Vondrak et al., 2008). The particles are formed by homogeneous nucleation, grow through coagulation, are transported to lower altitudes by sedimentation and winds and can ultimately be deposited out at the surface. Iron oxide $\left(\mathrm{FeO}, \mathrm{Fe}_{2} \mathrm{O}_{3}\right.$ and $\left.\mathrm{Fe}_{3} \mathrm{O}_{4}\right)$ particles of extraterrestrial origin have been detected in air samples (Kopcewicz \& Kopcewicz, 1996) and ice cores (Lanci et al., 2007) whilst silica $\left(\mathrm{SiO}_{2}\right)$ particles of both terrestrial and extraterrestrial origin have been implicated in the heterogeneous nucleation of stratospheric aerosol (Bogdan and Kulmala, 1999; Bogdan, 2000). As for magnesium oxide, no direct detection of this composition has to date been made in MSPs but laboratory work on oxidation pathways of $\mathrm{Mg}$ atoms (Plane \& Helmer, 1995) and consideration of similar chemical processes in circumstellar environments (Köhler et al., 1996) indicate a possible role for $\mathrm{MgO}$ nucleation.

Two separate experimental sessions were performed at the AIDA chamber. The first took place over the period of a week in December 2007 (all data sets for this session are referred to in the following discussion by the prefix IN11). These experiments focused on an inter-comparison of the ice nucleation potential of 3 different forms of iron oxide $\left(\mathrm{Fe}_{2} \mathrm{O}_{3}\right)$ powders: (i) an amorphous, laboratory-generated powder collected from the photo-oxidation of iron pentacarbonyl $\left\{\mathrm{Fe}(\mathrm{CO})_{5}\right\}$ vapour in the presence of ozone in an aerosol reactor system at the University of Leeds (Saunders and Plane, 2006); (ii) a high purity (99.999\%, Sigma-Aldrich 529311) crystalline sample and (iii) a sample of 'pseudocubic' $\mathrm{Fe}_{2} \mathrm{O}_{3}$ synthesised by a gel-sol process (Sugimoto and Sakata, 1992) in Karlsruhe. Figure 1 (top panel) shows an image of photo-chemically generated particles collected on a holey carbon TEM grid. The pseudocubic sample consisted of monodisperse crystalline particles with an edge length of $\sim 0.6$ microns (Fig. 1, bottom panel) - the interested reader is

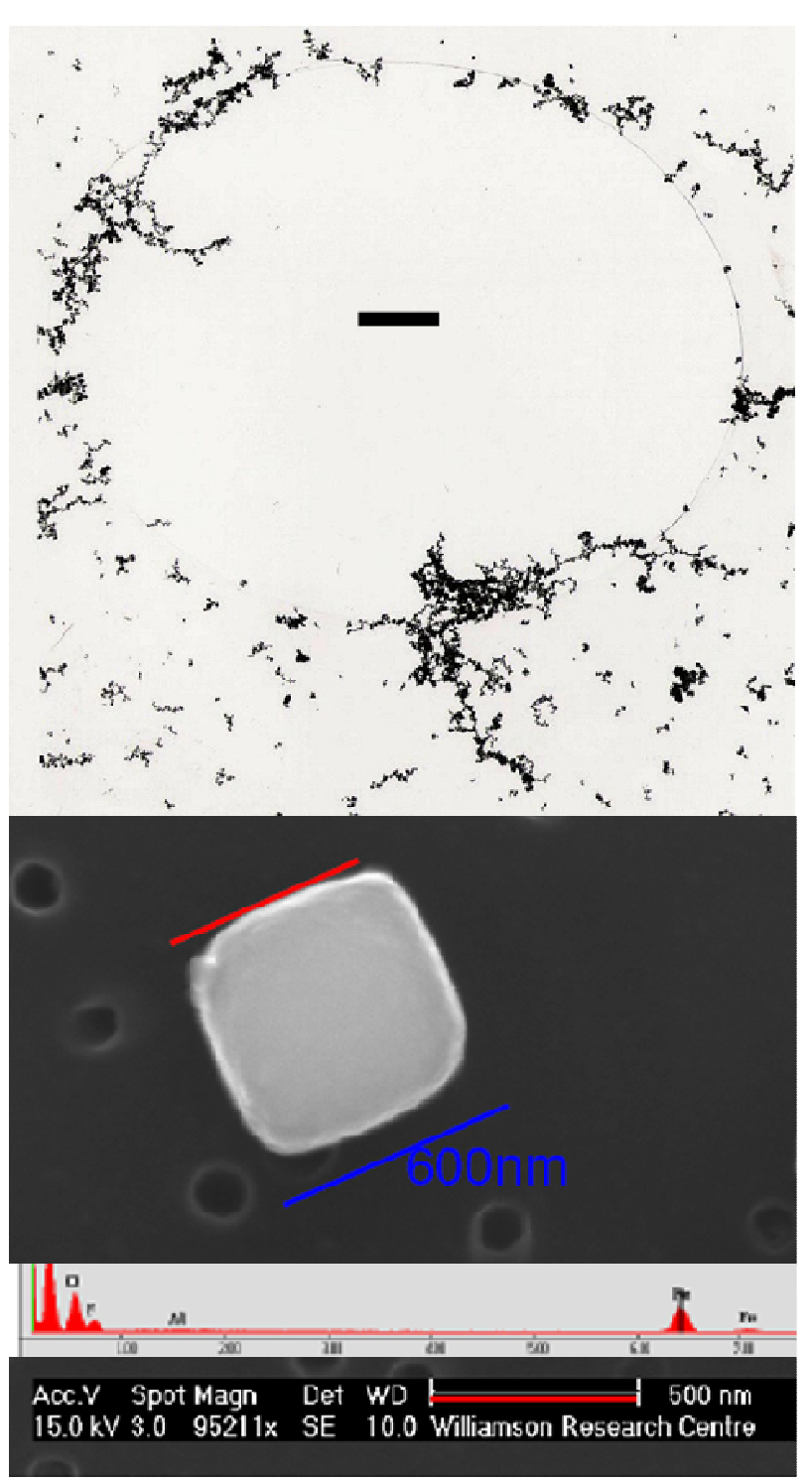

Fig. 1. (Top) Electron micrograph of amorphous iron oxide particles generated photo-chemically (scale bar in centre represents 2 microns). Deposited powder (referred to in the text as "IronOxide1") and in-situ generated particles were both used in ice nucleation experiments. (Bottom) Scanning electron micrograph and $\mathrm{x}$ ray spectrum of a single crystal of the pseudocubic hematite sample described in Sect. 2.

directed to Park et al. (1996) for a detailed discussion of the morphology of such particles.

The second session at the chamber took place over two weeks in June 2008. All data sets for this session are referred to in the following discussion by the prefix IN12. For these experiments, commercial powders of $\mathrm{MgO}$ and $\mathrm{SiO}_{2}$ (Sigma Aldrich 549649 \& S5130 respectively), and nanoparticles of $\mathrm{Fe}_{2} \mathrm{O}_{3}$ composition, generated in situ adjacent to the chamber using the same aerosol system as mentioned previously, were used for nucleation tests. 


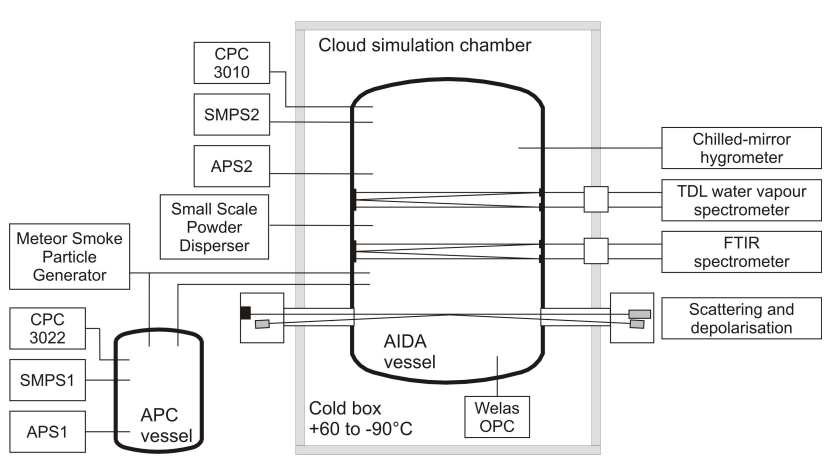

Fig. 2. Block schematic of the chamber and instrument set-up used to study the ice nucleating properties of the refractory nanoparticle samples - see Sect. 3 for definitions of all acronyms shown in the figure.

\section{Experimental procedure and instrumentation}

Figure 2 is a schematic diagram of the AIDA chamber and diagnostic instruments used for the experiments discussed here. Ice crystals are formed and observed in the central cylindrical chamber ( $4 \mathrm{~m}$ diameter, $84 \mathrm{~m}^{3}$ volume), which is encased in a large thermally insulated box. Prior to each series of ice nucleation experiments, the chamber was evacuated to a pressure below $0.1 \mathrm{hPa}$, flushed several times between 1 and $10 \mathrm{hPa}$, and filled with particle-free dry synthetic air. This procedure kept the aerosol background concentration typically below $0.1 \mathrm{~cm}^{-3}$. The chamber system was humidified by adding a certain amount of water vapour to the evacuated chamber to achieve partial ice coverage on the inner chamber walls. At constant temperature and pressure conditions, the ice coverage maintains a high relative humidity between 90 and $95 \%$ in the chamber volume, which is stirred with a mixing fan operated in the bottom part of the chamber.

Aerosols were either added directly to the AIDA chamber or first added to the $3.7 \mathrm{~m}^{3}$ large stainless steel Aerosol Preparation and Characterisation (APC) chamber and then partially transferred into the larger AIDA chamber for the ice nucleation experiments. The APC chamber was also used to test the aerosol generators and to comprehensively investigate and characterise the resulting aerosols. During IN11, dry powder samples were dispersed with a Small Scale Powder Disperser (SSPD, TSI Inc.) and added directly to the AIDA chamber. During IN12, small agglomerates of nanometer-sized oxide particles were generated in situ as surrogates of meteor smoke particles and added to both the APC and AIDA chambers for aerosol characterisation and ice nucleation experiments, respectively. Aerosol number and size distribution measurements were performed with a modified CPC (condensation particle counter), SMPS (scanning mobility particle spectrometer) and APS (aerodynamic particle spectrometer) from TSI Inc. Comparison between the SMPS and APS data was made through conversion of the aerodynamic particle size (APS) to an equivalent mobility size (SMPS) using an appropriate particle density $(\rho)$ and dynamic shape factor $(\chi)$ - see Möhler et al. (2006). Values of $\rho\left(\mathrm{g} \mathrm{cm}^{-3}\right)$ used for the samples described in Sect. 2 were: $5.0\left(\mathrm{Fe}_{2} \mathrm{O}_{3}\right.$ - crystalline), $2.0\left(\mathrm{Fe}_{2} \mathrm{O}_{3}\right.$ - amorphous), $2.2\left(\mathrm{SiO}_{2}\right)$ and $3.6(\mathrm{MgO})$, whilst $\chi$ values of $1.5-1.6$ were chosen (see DeCarlo et al. (2004) for more detailed discussion of this parameter).

The efficiencies of the various aerosols to act as ice nuclei in the deposition mode of heterogeneous ice nucleation were investigated in a series of expansion runs, using techniques and protocols established for AIDA cloud simulation studies over the past few years (see Möhler et al., 2003, 2005, 2006 and 2008 for details of chamber operation). The water vapour partial pressure is measured with a fast and sampling-free open-path tunable diode laser (TDL) absorption spectrometer (Ebert et al., 2005). In addition, a chilled mirror frost point hygrometer (MBW Calibration Ltd) measures the total water concentration in the chamber system.

During the course of an expansion experiment, the ice formation by aerosol particles is observed as a function of the changing temperature and ice saturation ratio $\left(s_{\text {ice }}\right) /$ relative humidity with respect to ice (RHi). Ice crystals are detected and measured with an in situ light scattering and depolarization setup for the sensitive detection of droplet and ice particle growth, an infrared extinction spectrometer (FTIR) (Wagner et al., 2006; 2007), and two optical particle counters (Welas, Palas $\mathrm{GmbH}$ ) (Benz et al., 2005). The aerosol number concentration is continuously measured with a condensation particle counter (CPC3010, TSI Inc.) modified for operation at low pressure and temperature (Seifert et al., 2004). Aerosol size distributions were only obtained at atmospheric pressure before starting the expansion run. Ice active aerosol particle fractions $\left(f_{\text {ice }}\right)$ were calculated as the ratio of the ice particle to aerosol particle number concentration and were used as an initial measure of efficiency of the various aerosols to act as deposition mode ice nuclei.

\section{Results}

\subsection{IN11 $\left(\mathrm{Fe}_{2} \mathrm{O}_{3}\right.$ powders $)$}

Figure 3 shows a direct comparison of ice nucleation data sets obtained for the powder produced photo-chemically in the laboratory (left panel - labelled "IronOxide-1") and the commercial $\mathrm{Fe}_{2} \mathrm{O}_{3}$ powder (right panel - labelled "IronOxide-2") for the same initial chamber temperature of $\sim 214 \mathrm{~K}$.

The top panel in each case shows the variation in chamber air temperature (blue line) and pressure (black line) throughout an experimental run while the dot-dash red line shows the stability of the temperature of the chamber walls. The next panel down shows the temporal variation in relative 

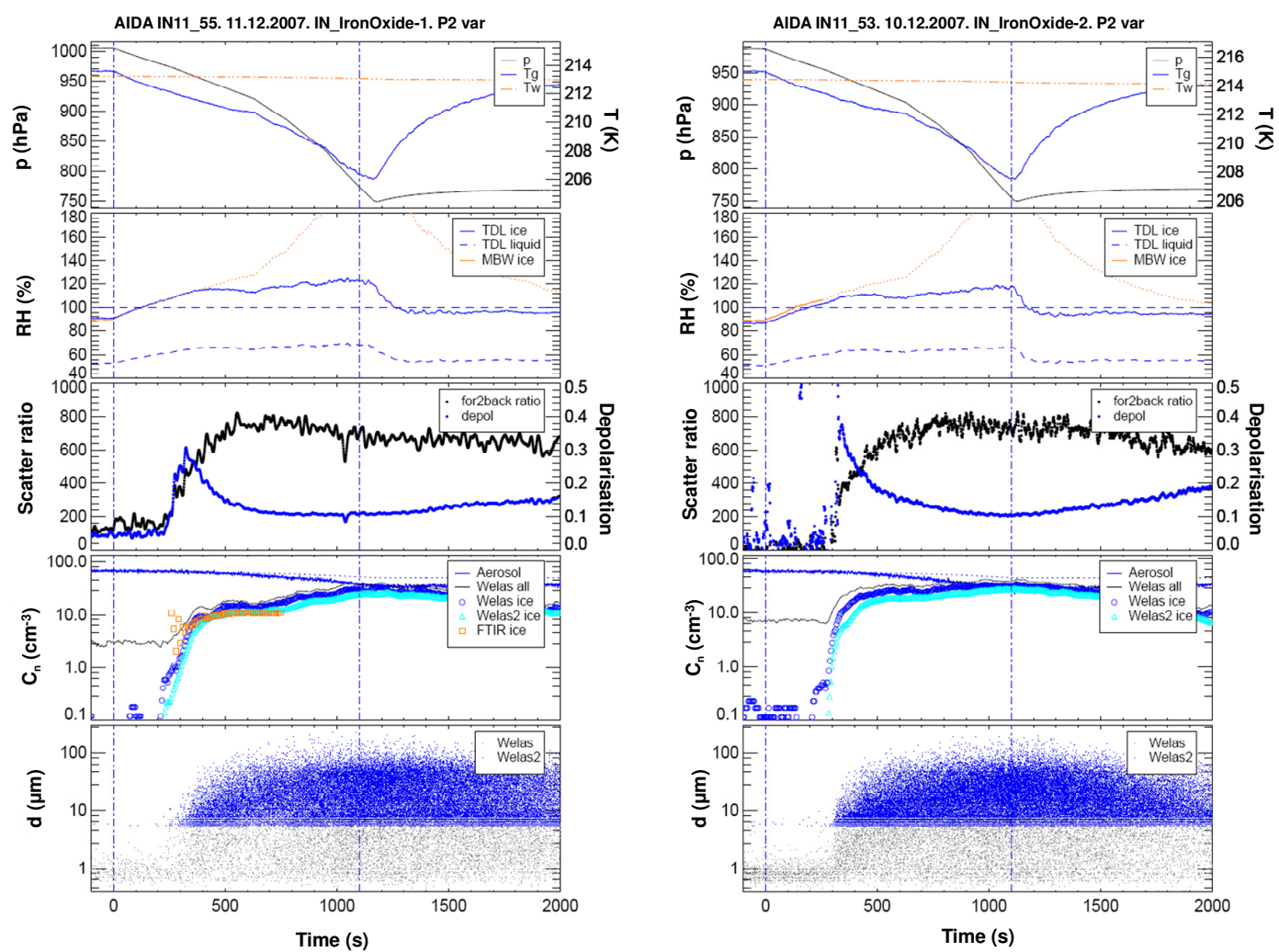

Fig. 3. AIDA chamber ice nucleation data (IN11, \#55 - left and \#53 - right) for $\mathrm{Fe}_{2} \mathrm{O}_{3}$ powders: left-hand side is for laboratory generated aerosol and right-hand side for the commercial sample (see Fig. 1 and text). The initial chamber air temperature $\left(T_{i}\right)$ was $\sim 214 \mathrm{~K}$ as indicated by the blue line at $t=0 \mathrm{~s}$ in the top panel of each data set. See text for further explanation of panel data and details of initial particle size distributions.

humidity (RH) with respect to ice (RHi, solid blue line) and liquid water (RHw, dashed blue line below $\mathrm{RH}=100 \%)$, both measured with the TDL system; "MBW" refers to frost point measurements taken with the chilled-mirror hygrometer. This instrument samples air from the cloud chamber through a heated stainless steel tube and therefore measures the total (gas- + condensed-phase) water concentration. The third panel shows the in-situ $\mathrm{Ar}^{+}$laser data with the black line indicating the ratio of forward $\left(2^{\circ}\right)$ to backward $\left(178^{\circ}\right)$ scattering at $488 \mathrm{~nm}$, while the blue line shows the change in depolarisation determined from backscattering perpendicular and parallel to the direction of linear polarisation of the laser, with increasing values corresponding to increasing non-spherical morphology resulting from ice crystal growth. The fourth panel gives the change in total aerosol particle concentration (blue line) and total ice particle concentration (black line). Also shown are the ice particle concentrations as measured by the WELAS\#1 instrument (blue circles), from the second WELAS\#2 detector, indicated by light blue triangles, and from the in-situ FT-IR spectrometer (orange squares). Finally, the bottom panel in each data set shows the single particle data from the two WELAS detectors as indicated in the panel caption. Each dot (grey - WELAS1, blue - "WELAS 2") in this plot results from detection of a single ice particle at a specific size as indicated on the vertical axis and consequently the density of data points gives an indication of the concentration of detected ice particles at a particular size and time. All data is plotted with respect to the time $(t)$ for which an experiment was conducted in the chamber.

Measured initial smoke particle size distributions in the chamber were fitted with the following log-normal parameters ( $\sum N$ - total particle concentration, $D_{m}$ - modal size and $\sigma$ - geometric standard deviation); laboratory $\mathrm{Fe}_{2} \mathrm{O}_{3}-$ $\sum N=60 \mathrm{~cm}^{-3}, D_{m}=162 \mathrm{~nm}$ and $\sigma=2.1$ and commercial $\mathrm{Fe}_{2} \mathrm{O}_{3}-\sum N=58 \mathrm{~cm}^{-3}, D_{m}=260 \mathrm{~nm}$ and $\sigma=2.1$. In both experiments, RHw was maintained well below saturation.

Figure 4 summarises the variation in the ice number fraction, $f_{\text {ice }}$ (ratio of the number of detected ice particles to the total initial concentration of aerosol particles injected into the chamber) as a function of RHi, taking into account the aerosol dilution effect during pumping (pressure change). Whilst some particle losses to the chamber walls (small particles) and settling to the bottom of the chamber (largest particles) are likely to occur as a result of such pumping, on the timescale of a typical expansion run with ice cloud formation these losses will be sufficiently small ( $<5 \%$ of total) to have any significant impact on the analysis and conclusions 


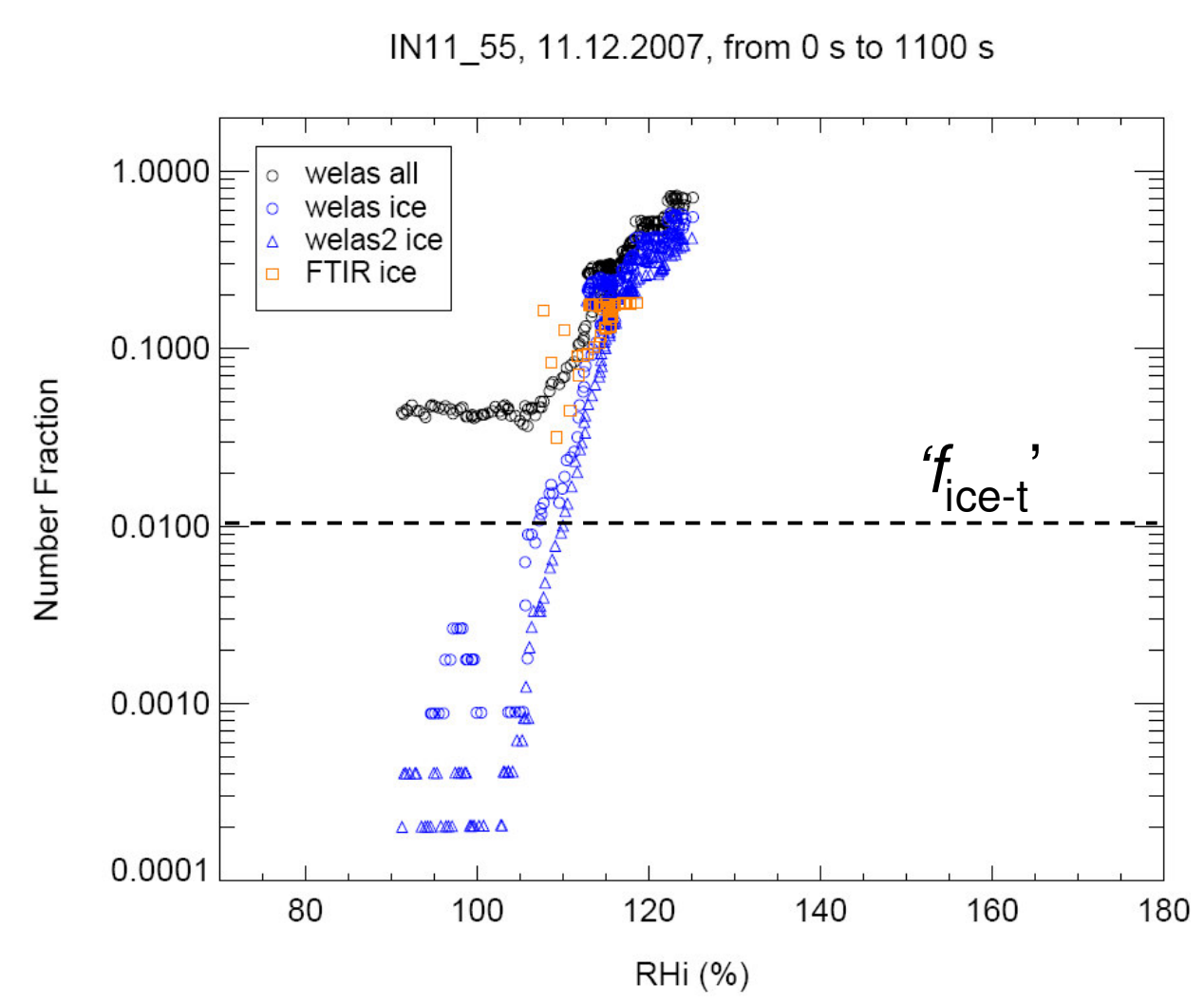

IN11_53, 10.12.2007, from $0 \mathrm{~s}$ to $1100 \mathrm{~s}$

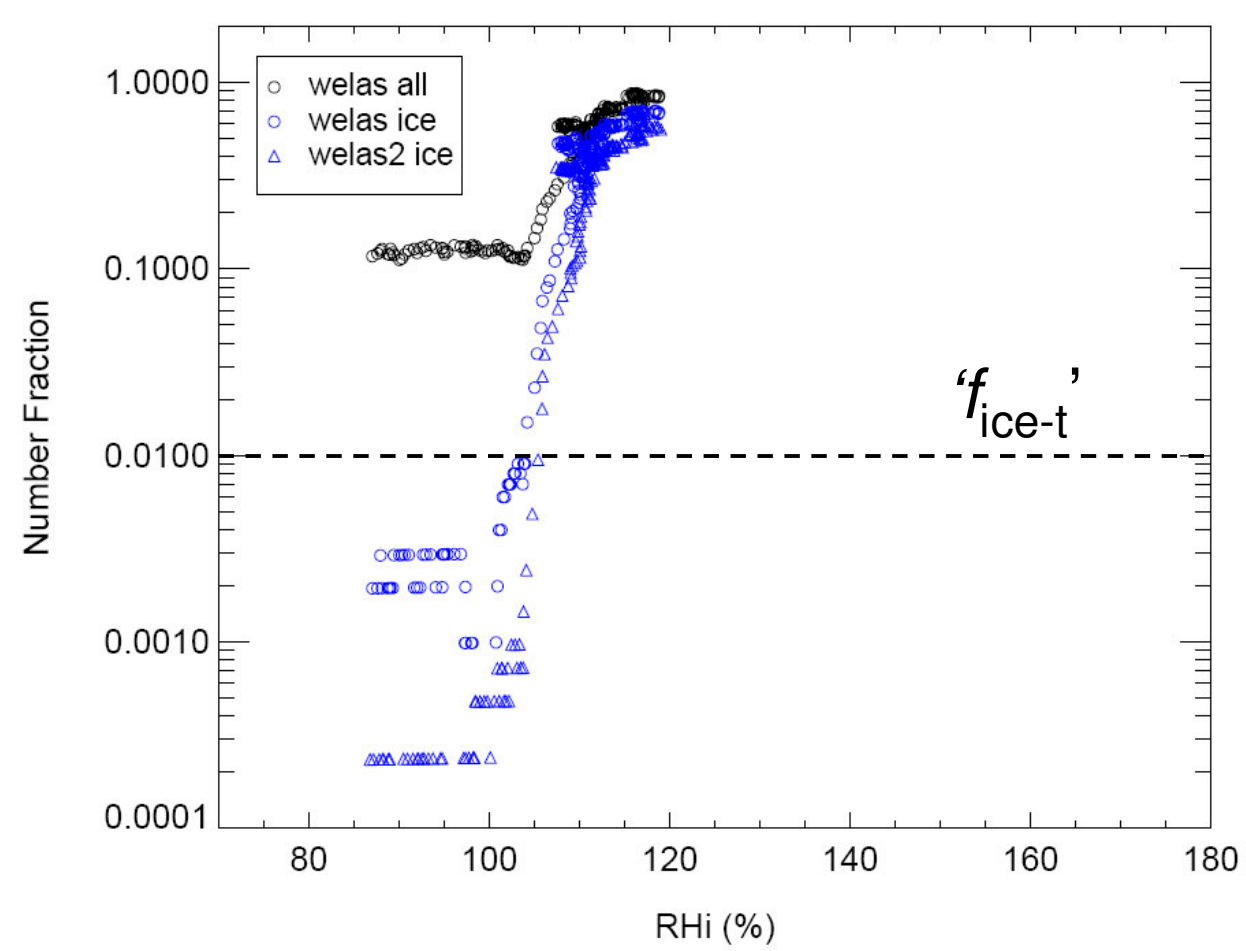

Fig. 4. Variation of ice number fraction with relative humidity (with respect to ice) calculated from data in Fig. 3 ( $f_{\text {ice }-\mathrm{t}}$ refers to a defined threshold level of $1 \%$ of the initial aerosol number). 

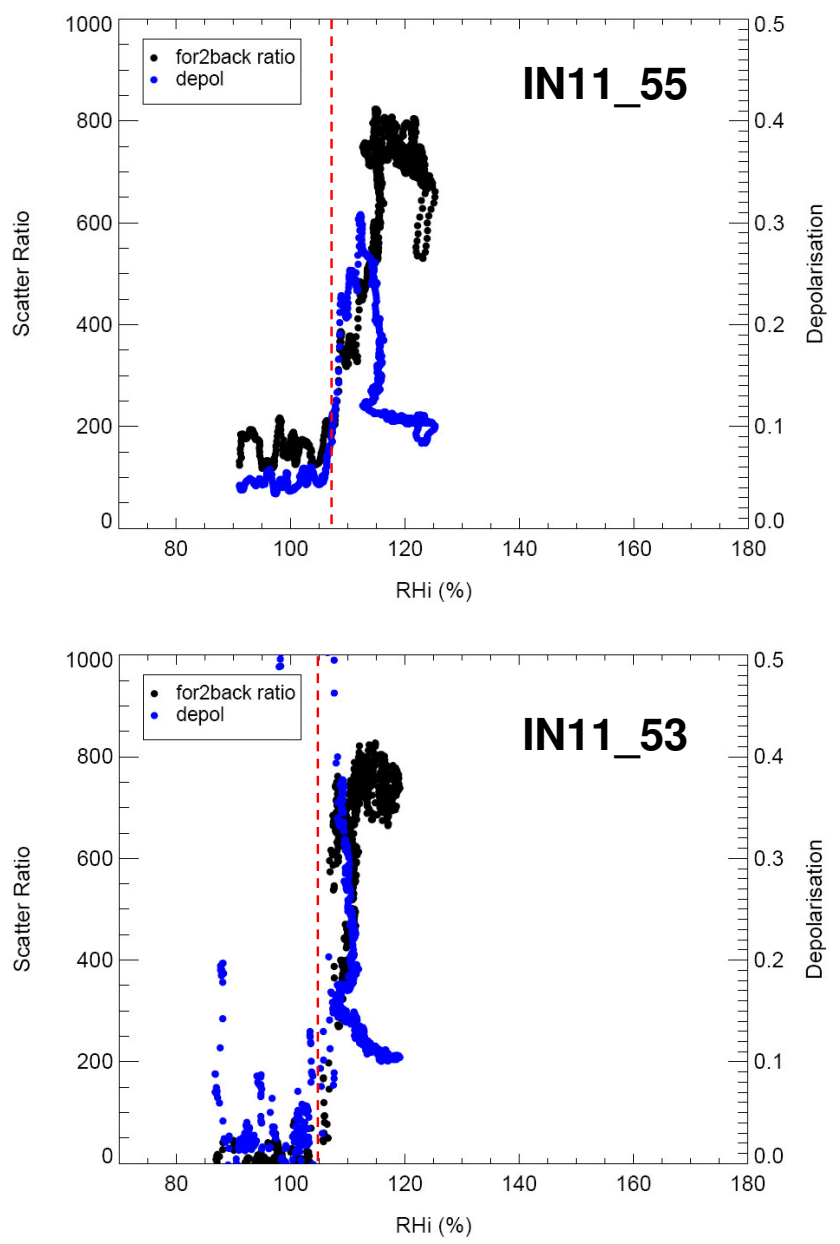

Fig. 5. Variation of light scatter (forward: back) ratio with relative humidity (ice) for nucleation experiments $\left(T_{i}=214 \mathrm{~K}\right)$ with laboratory-generated (top panel) and commercial (bottom panel) iron oxide powders. The dashed red lines indicate the $\mathrm{RH}_{i}$ values at which $f_{\text {ice }}$ exceeds 0.01 in the respective experiment.

made. The nucleation data for the respective powder samples is plotted for a time period indicated at the top of each panel (in this case, the same time span), corresponding to the vertical dot-dash blue lines in Fig. 3.

In the case of the laboratory produced $\mathrm{Fe}_{2} \mathrm{O}_{3}$ sample (top panel), a defined threshold ice number fraction $\left(f_{\text {ice }-\mathrm{t}}\right.$ : $\left.f_{\text {ice }}=0.01\right)$ occurs $\sim 300 \mathrm{~s}$ after the expansion cycle was started, corresponding to RHi $\sim 107 \%$ and increases with increasing RHi to a maximum value $\left(f_{\text {ice }-\max }\right)$ of $\sim 0.8$. For the commercial $\mathrm{Fe}_{2} \mathrm{O}_{3}$ aerosol, $f_{\text {ice-t }}$ occurs at around the same time as the laboratory produced sample at $\sim 105 \%$ RHi with $f_{\text {ice }-\max }=0.85$. These "critical" RHi levels (also see Table 1) are further verified by the in situ laser scattering data shown in Fig. 5 where the scattering ratio increases significantly as does the depolarisation at the stated RHi values as indicated by the dashed red lines in this figure.
Figure 6 shows the ice fraction and laser scattering data for the same two $\mathrm{Fe}_{2} \mathrm{O}_{3}$ samples but this time from experiments conducted at a lower initial chamber temperature of $192-193 \mathrm{~K}$. Measured initial smoke particle size distribution parameters were $\sum N=150 \mathrm{~cm}^{-3}, D_{m}=68 \mathrm{~nm}$ and $\sigma=2.0$ (laboratory: left-hand panels) and $\sum N=100 \mathrm{~cm}^{-3}$, $D_{m}=233 \mathrm{~nm}$ and $\sigma=1.8$ (commercial).

At the lower temperature, for both samples, $f_{\text {ice- } t}$ takes longer to occur after the expansion cycle is initiated and significantly lower $f_{\text {ice-max }}$ values $(0.12$ for the laboratory sample and 0.5 for the commercial sample) are evident than at the warmer temperature. The commercial powder shows a relatively fast increase in $f_{\text {ice }}$, scatter ratio and depolarisation above RHi $\sim 125 \%$ (panels b \& d) whilst the data for the laboratory-generated powder shows significantly greater scatter, although it is still evident from the increased density of data points that a critical RHi occurs at $\sim 140 \%$.

Finally, Fig. 7 shows the variation in $f_{\text {ice }}$ with RHi for the pseudocubic (monodisperse) $\mathrm{Fe}_{2} \mathrm{O}_{3}$ particles at an initial chamber temperature of $192 \mathrm{~K}$. In this case, $f_{\text {ice }-\mathrm{t}}$ occurs after $\sim 600$ s, at RHi $\sim 130 \%$ with $f_{\text {ice- } \max } \sim 0.8$.

\subsection{IN12( $\mathrm{Fe}_{2} \mathrm{O}_{3}$ nanoparticles and $\mathrm{MgO} / \mathrm{SiO}_{2}$ powders $)$}

Figure 8 gives data sets for the $\mathrm{Fe}_{2} \mathrm{O}_{3}$ nanoparticles generated in-situ at the chamber. Both experiments were conducted at an initial temperature of $\sim 246 \mathrm{~K}$ but in the case of the right-hand set, the initial air pressure was significantly lower $(\sim 760 \mathrm{hPa})$ than that normally used $(\sim 1000 \mathrm{hPa})$, as was the minimum pressure reached in the expansion cycle. Measured initial size distributions parameters were $\sum N=150 \mathrm{~cm}^{-3}, D_{m}=23 \mathrm{~nm}$ and $\sigma=1.5$ (left) and $\sum N=40 \mathrm{~cm}^{-3}, D_{m}=21 \mathrm{~nm}$ and $\sigma=1.3$ (right).

At this warmer temperature, two nucleation modes (liquid droplets and ice particles) are evident in the bottom 2 panels of each data set, overlapping in the higher pressure run but resolved under the lower pressure conditions. In these panels, the symbols represent the ice particle measurements with the two WELAS instruments, whilst the grey line shows the total (droplet + ice particle) number. It appears that water droplets nucleate first, followed by ice particles at lower temperatures.

Figure 9 summarises the variation in the calculated nucleated number fraction $f$ (droplet and ice) as a function of RHi (panel a) and RHw (panel b) from the experiment at higher pressure (Fig. 8, left-hand data set) for $t=0-750 \mathrm{~s}$. Droplet formation exceeds the defined threshold limit $\left(f_{\text {ice }-\mathrm{t}}=0.01\right)$ at below 100\% RHw/130\% RHi (dotted red lines), and ice formation at $\sim 100 \%$ RHw/140\% RHi (dashed red lines) with a maximum total $f$ of $\sim 0.3$.

From panel (c), $f_{t}$ occurs at $\sim 241 \mathrm{~K}$ (droplet) and $237.5 \mathrm{~K}$ (ice), whilst panel (d) illustrates the cycle of RHi values attained in the experiment (orange line). Also shown for comparison in this last panel, are the data for liquid water saturation (solid blue line - calculated from Murphy and Koop, 

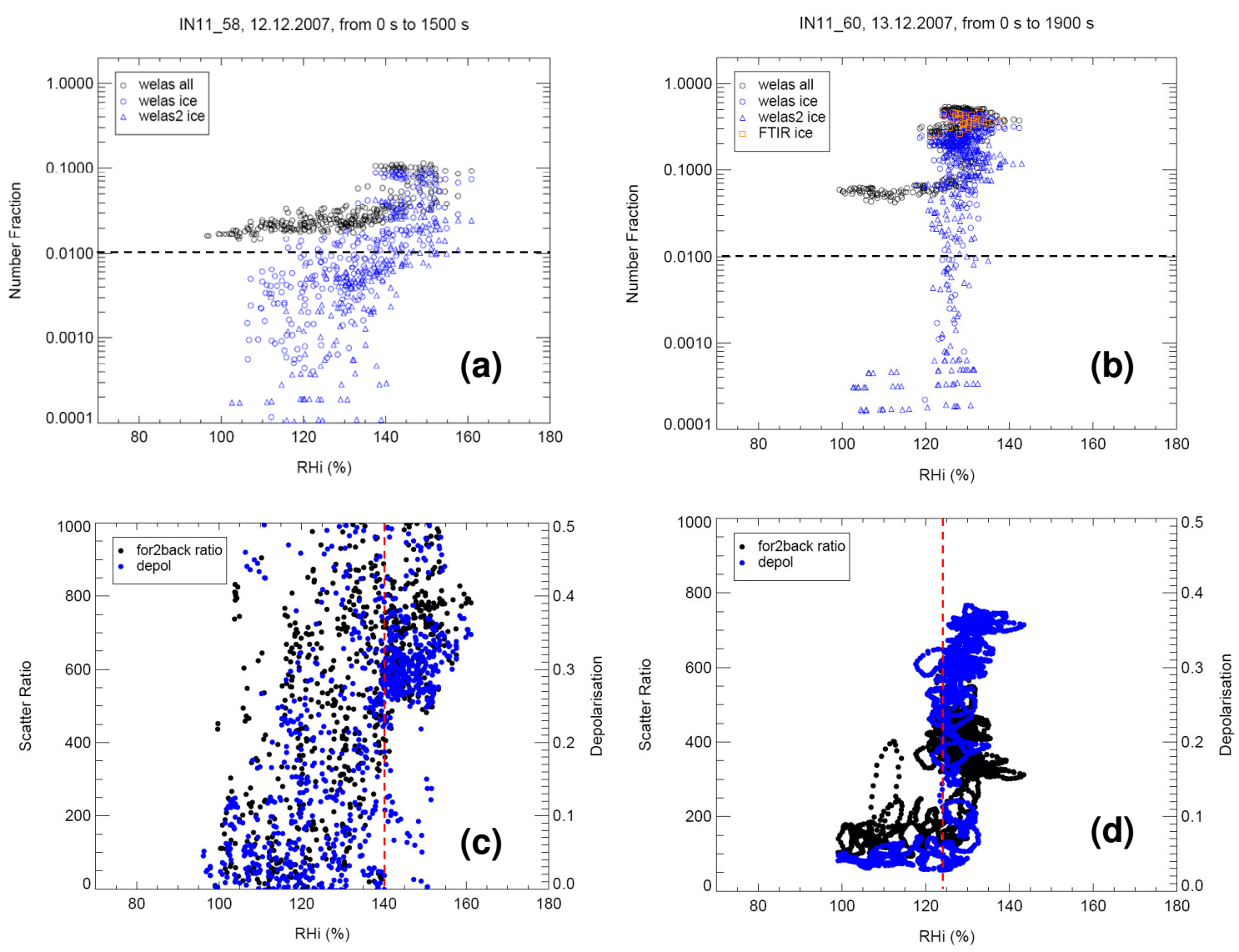

Fig. 6. Ice number fraction and laser scatter plots from nucleation experiments (IN11, \#58 - left and \#60 - right) carried out on laboratorygenerated (panels (a) and (c)) and commercial (panels (b) and (d)) iron oxide powders at $T_{i}=193 \mathrm{~K}$.

2005) and for solution droplet homogeneous freezing at two different water activity offset values $\left(\Delta a_{w}\right)$ of 0.3 (lower dashed blue line) and 0.32 (upper dashed blue line) - see Koop et al. (2000) and Möhler et al. (2008).

These results indicate that $\mathrm{Fe}_{2} \mathrm{O}_{3}$ particles do not nucleate ice below water saturation, but do serve as condensation nuclei $(\mathrm{CN})$ at $241 \mathrm{~K}$. These droplets then activated to ice at below $238 \mathrm{~K}$. This is close to the temperature at which ice nucleates homogeneously within water droplets. This is a surprising result since it might be expected that water droplets contaminated with solid iron oxide particles would freeze heterogeneously.

In order to investigate the apparent inactivity of $\mathrm{Fe}_{2} \mathrm{O}_{3}$ particles when immersed in water droplets, we performed a series of separate experiments using a microscope equipped with a specialised cold stage. In this system, which is described elsewhere (Murray et al., 2010), droplets containing a known concentration of contaminating particles were placed on a hydrophobic surface and cooled down while monitoring for ice nucleation using the optical microscope. Tests with pure water droplets free of any solid impurities showed that this substrate did not nucleate ice heterogeneously and the droplets $(\sim 10-30 \mu \mathrm{m}$ diameter $)$ froze at the homogeneous limit between $236 \pm 0.5$ and $234 \pm 0.5 \mathrm{~K}$. Droplets contaminated with up to $0.05 \mathrm{wt} \%$ of the same laboratory generated $\mathrm{Fe}_{2} \mathrm{O}_{3}$ particles and up to $1 \mathrm{wt} \%$ of the commercial $\mathrm{Fe}_{2} \mathrm{O}_{3}$ nanopowder used in the AIDA studies, also only nucleated at the homogeneous limit. Contamination of droplets with similar quantities of clay minerals such as illite causes ice to nucleate some $10 \mathrm{~K}$ higher (Murray et al., 2010). These results confirm that $\mathrm{Fe}_{2} \mathrm{O}_{3}$ particles are inactive in the immersion mode in pure water droplets.

Figure 10 shows nucleation data for $\mathrm{Fe}_{2} \mathrm{O}_{3}$ nanoparticles generated in-situ at the lower temperatures of $200 \mathrm{~K}$ (LHS) and $182 \mathrm{~K}$ (RHS) - please refer to Table 1 for a summary of threshold values. Measured initial size distributions parameters were $\sum N=120 \mathrm{~cm}^{-3}, D_{m}=27 \mathrm{~nm}$ and $\sigma=1.5$ (LHS) and $\sum N=110 \mathrm{~cm}^{-3}, D_{m}=27 \mathrm{~nm}$ and $\sigma=1.5$ (RHS).

Finally, Fig. 11 compares the number fraction data (top panels: against RHi, bottom panels: against $T$ ) for the commercial $\mathrm{MgO}$ (left-hand side) and $\mathrm{SiO}_{2}$ (right-hand side) powders dispersed into the chamber at an initial temperature of 199-200 K. Measured initial size distributions parameters were $\sum N=700 \mathrm{~cm}^{-3}, D_{m}=140 \mathrm{~nm}$ and $\sigma=2.2(\mathrm{MgO})$ and $\sum N=55 \mathrm{~cm}^{-3}, D_{m}=111 \mathrm{~nm}$ and $\sigma=2.1\left(\mathrm{SiO}_{2}\right)$. Again, threshold values are given in Table 1 . 
Table 1. Comparison of Nucleation Data for Different Forms ((A) composition, (B) size and (C) morphology) of Refractory Particles.

\begin{tabular}{|c|c|c|c|c|c|c|}
\hline & $\begin{array}{l}\text { Exp. \# } \\
\text { (Figure \#) }\end{array}$ & $\begin{array}{l}\text { (a) } \\
T_{i} \\
(\mathrm{~K})\end{array}$ & $\begin{array}{l}\text { (b) } \\
D_{m} \\
(\mathrm{~nm})\end{array}$ & $\begin{array}{l}\text { (c) } \\
t \\
\text { (thresh) } \\
\text { (s) }\end{array}$ & $\begin{array}{l}(\mathrm{d}) \\
\mathrm{RH}_{i} \\
\text { (thresh) } \\
(\%)\end{array}$ & $\begin{array}{l}(\mathrm{e}) \\
f_{\text {ice-max }} \\
\left(\% \mathrm{RH}_{\mathrm{i}-\max }\right)\end{array}$ \\
\hline (A) & IN11_60 & 192 & 233 & 500 & 125 & 0.50 \\
\hline $\begin{array}{l}\mathrm{Fe}_{2} \mathrm{O}_{3} \\
\text { (commercial) }\end{array}$ & $\begin{array}{l}(6) \\
\text { IN11_53 } \\
(3-5)\end{array}$ & 215 & 260 & 300 & 105 & $\begin{array}{l}(135) \\
0.85 \\
(115)\end{array}$ \\
\hline $\mathrm{MgO}$ & $\begin{array}{l}\text { IN12_03 } \\
(11)\end{array}$ & 200 & 140 & 450 & 120 & $\begin{array}{l}0.08 \\
(125)\end{array}$ \\
\hline $\mathrm{SiO}_{2}$ & $\begin{array}{l}\text { IN12_21 } \\
(11)\end{array}$ & 200 & 111 & 150 & 118 & $\begin{array}{l}0.50 \\
(160)\end{array}$ \\
\hline $\begin{array}{l}(\mathrm{B}) \\
\mathrm{Fe}_{2} \mathrm{O}_{3} \\
\text { (powder) }\end{array}$ & $\begin{array}{l}\text { IN11_55 } \\
(3-5) \\
\text { IN11_58 } \\
(6)\end{array}$ & $\begin{array}{l}213 \\
193\end{array}$ & $\begin{array}{l}162 \\
68\end{array}$ & $\begin{array}{l}300 \\
1000\end{array}$ & $\begin{array}{l}107 \\
140\end{array}$ & $\begin{array}{l}0.80 \\
(120) \\
0.12 \\
(160)\end{array}$ \\
\hline $\begin{array}{l}\mathrm{Fe}_{2} \mathrm{O}_{3} \\
\text { (nanoparticles) }\end{array}$ & $\begin{array}{l}\text { IN12_17 } \\
(10) \\
\text { IN12_09 } \\
(10)\end{array}$ & $\begin{array}{l}200 \\
182\end{array}$ & $\begin{array}{l}27 \\
27\end{array}$ & $\begin{array}{l}500 \\
800\end{array}$ & $\begin{array}{l}125 \\
140\end{array}$ & $\begin{array}{l}0.02 \\
(180) \\
0.09 \\
(170)\end{array}$ \\
\hline $\begin{array}{l}(\mathrm{C}) \\
\mathrm{Fe}_{2} \mathrm{O}_{3} \\
\text { (amorphous) }\end{array}$ & $\begin{array}{l}\text { IN11_58 } \\
(6)\end{array}$ & 193 & 68 & 1000 & 140 & $\begin{array}{l}0.12 \\
(160)\end{array}$ \\
\hline $\begin{array}{l}\mathrm{Fe}_{2} \mathrm{O}_{3} \\
\text { (crystalline } \\
\text { - hexagonal) }\end{array}$ & $\begin{array}{l}\text { IN11_60 } \\
(6)\end{array}$ & 192 & 233 & 500 & 125 & $\begin{array}{l}0.50 \\
(135)\end{array}$ \\
\hline $\begin{array}{l}\mathrm{Fe}_{2} \mathrm{O}_{3} \\
\text { Pseudocubic }\end{array}$ & $\begin{array}{l}\text { IN11_62 } \\
(7)\end{array}$ & 192 & $\begin{array}{l}600 \\
\text { (edge) }\end{array}$ & 600 & 130 & $\begin{array}{l}0.80 \\
(150)\end{array}$ \\
\hline
\end{tabular}

(a) $-T_{i}$ : initial temperature of air in AIDA chamber prior to expansion cycle

(b) $-D_{m}$ : modal diameter of measured aerosol size distribution

(c) $-t$ (thresh): "threshold" nucleation time for fraction of initial aerosol to be detected as ice particles $\left(f_{\text {ice }}\right)>0.01$

(d) $-\mathrm{RH}_{i}$ (thresh): relative humidity with respect to ice in the chamber at $t_{\text {thresh }}$

(e) $-f_{\text {ice-max }}:$ maximum value of $f_{\text {ice }}$ in experimental run, $\mathrm{RH}_{\mathrm{i}-\text { max }}$ : maximum relative humidity with respect to ice reached in the chamber

\section{Discussion}

For an initial analysis of the nucleation data for the different aerosol samples described in Sect. 2, we will focus on the three primary properties which are likely to affect threshold conditions of relative humidity with respect to ice $\left(\mathrm{RH}_{i}\right)$ and the calculated fraction $\left(f_{\text {ice }}\right)$ of initial aerosol particles which initiate ice crystal formation in each case. These critical particle properties are (a) composition, (b) size and (c) structure/morphology.

\subsection{Particle composition}

Table 1 - section A summarises the data for the first of the stated aerosol properties by comparing the commer- cially available iron, magnesium and silicon oxide powders that were investigated. Two data sets are shown for $\mathrm{Fe}_{2} \mathrm{O}_{3}$ ("IronOxide-2"), because the initial air temperatures in the chamber $\left(T_{i}\right)$ for those experiments straddle the $200 \mathrm{~K}$ temperature used in the experiments on the other oxides.

It can be seen that the $\mathrm{SiO}_{2}$ particles seem to have similar nucleation properties to the $\mathrm{Fe}_{2} \mathrm{O}_{3}$ sample at $200 \mathrm{~K}$, in terms of the experimental observables of threshold $\mathrm{RH}_{i}$ (for $f>0.01)$ and $f_{\text {ice-max }}$. Whilst there are many different structural forms of silica, which are likely to have very different water-adsorption and ice nucleating propensities, the amorphous form used in these studies is the most likely one to result via condensation from the gas-phase in the upper atmosphere. The sample used has a high quoted surface area of $\sim 390 \mathrm{~m}^{2} \mathrm{~g}^{-1}$ and consists of aggregated chains of $\sim 7 \mathrm{~nm}$ 
IN11_62, 14.12.2007, from $0 \mathrm{~s}$ to $1900 \mathrm{~s}$

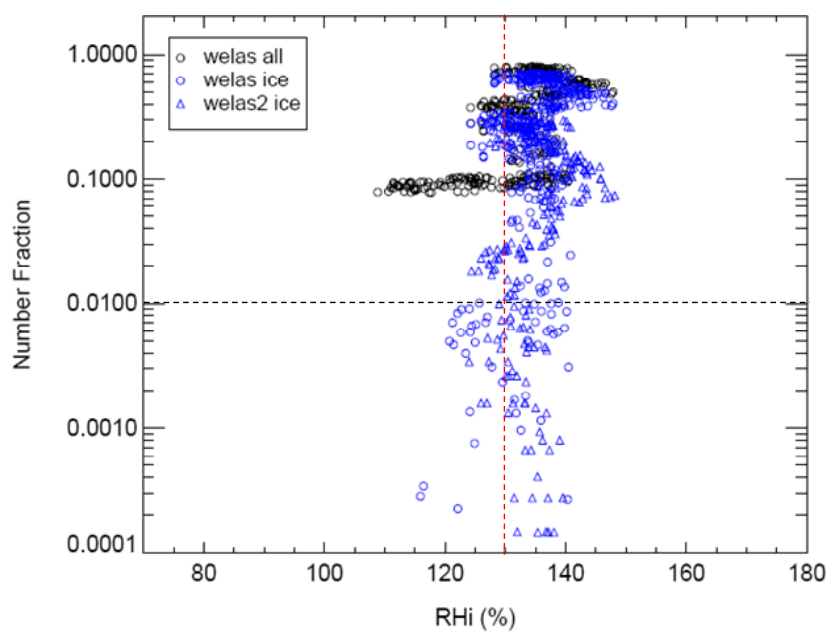

Fig. 7. Ice number fraction data for the pseudo-cubic $\mathrm{Fe}_{2} \mathrm{O}_{3}$ sample at $T_{i}=192 \mathrm{~K}$

primary particles which are of the order of a few tenths of a micron in dimension. It is likely that the dispersal method used for admitting aerosol in powder form into the AIDA chamber will result in some degree of break-up of such aggregates, reflected in the measured modal size of $111 \mathrm{~nm}$. The $\mathrm{Fe}_{2} \mathrm{O}_{3}$ particles from the dispersed commercial sample have a modal size almost twice that of the $\mathrm{SiO}_{2}$ indicating that particle size alone does not explain the relatively high efficiency of the silica aerosol, but composition and/or structural differences are more important factors.

The $\mathrm{MgO}$ sample appears to be a weaker candidate for ice nucleation in comparison with iron and silicon oxides at these temperatures. The sample used is quoted as consisting of nanoparticles of $<50 \mathrm{~nm}$ size and a surface area of $130 \mathrm{~m}^{2} \mathrm{~g}^{-1}$ although the measured modal size of $140 \mathrm{~nm}$ seems to indicate some degree of aggregation. A significantly lower $f_{\text {ice-max }}$ of 0.08 was observed, although it should be noted that the maximum RHi value of $125 \%$ for this chamber run was lower than those attained for the $\mathrm{Fe}_{2} \mathrm{O}_{3}$ and $\mathrm{SiO}_{2}$ samples at $200 \mathrm{~K}$ (see Table 1).

\subsection{Particle size}

Table 1 - section B compares data for the laboratorygenerated amorphous $\mathrm{Fe}_{2} \mathrm{O}_{3}$ samples ("Iron Oxide-1") in both powder form (mechanically dispersed into the chamber volume) and particle form (generated in situ adjacent to the chamber and passed directly into the chamber). Two $T_{i}$ runs are shown for each sample. These are not identical for the two particle forms but are close enough for reasonable inferences to be made.

It has been shown in previous work (Saunders and Plane, 2006) that the photo-oxidation of $\mathrm{Fe}(\mathrm{CO})_{5}$ in $\mathrm{O}_{3}$ leads to the formation of amorphous $\mathrm{Fe}_{2} \mathrm{O}_{3}$ particles which form chain- like aggregates of micron dimensions, consisting of primary particles of 6-7 nm diameter. Both of these aerosol samples were produced by this same method, although in order to sediment out enough powder for the subsequent nucleation experiments (IN11), the aerosol generator was run for much longer times and at much higher precursor concentrations and photolysis light intensities. The only difference expected therefore is that of particle/aggregate size as corroborated by the measured modal sizes. As mentioned before, the dispersal method used to admit the powder sample is likely to result in the mechanical break-up of the micron-size aggregates (see Fig. 1 - top panel). Indeed, the modal sizes of $<200 \mathrm{~nm}$ suggest that such break-up is significantly more pronounced than in the case of the $\mathrm{SiO}_{2}$ powder as discussed in the previous section.

For the powder sample, there is a marked decrease in $f_{\text {ice-max }}$ below $200 \mathrm{~K}$, although at $193 \mathrm{~K}$, still $\sim 12 \%$ of the initial aerosol population was observed to lead to ice crystal formation with RHi-max $=160 \%$. In contrast, the nanoparticles $\left(D_{m} \sim 30 \mathrm{~nm}\right)$ formed in situ showed lower activation levels although the lower temperature run did result in a higher activated fraction. This was probably a consequence of the more rapid increase in air temperature after $\sim 1500$ s of the $T_{i}=200 \mathrm{~K}$ run which resulted in a faster drop in $\mathrm{RH}_{i}$, hence most likely limiting any further activation of the aerosol population.

The lower values for the nanoparticles are consistent with the classical heterogeneous nucleation theory of Fletcher (1958) which predicts a pronounced size effect to ice nucleation directly from the vapour-phase for spherical particle sizes below $100 \mathrm{~nm}$. On this basis, for the case of a polydisperse initial aerosol distribution, it is reasonable to suppose that the larger particles within the distribution will nucleate ice formation sooner (at lower RHi) than the smaller particles. Whereas the particle size range for the powder sample extended up to a few hundreds of nanometers, for the nanoparticles formed in situ, the upper limit of the measured size range was $\sim 80 \mathrm{~nm}$ and so the observed maximum ice number fractions at a particular temperature/ice supersaturation were lower. In addition, the maximum RHi value reached in a particular nucleation run is a complex function of a number of factors including the rates of ice crystal formation and growth and the cooling rate within the chamber (Möhler et al., 2006). As such, the RHi increase within the chamber, after ice crystal formation has been initiated by the sample, is somewhat self-limiting and consequently, higher ice super-saturation $(>200 \%)$ conditions required for smaller particles within a distribution to nucleate ice are prevented. Therefore, the maximum reported ice number fractions for each experiment do not represent the "true" activation efficiency of a particular particle material. For this, it is more instructive to use the observed threshold RHi values for determination of the contact angle with respect to ice embryo formation at the particle surface, or the variation of $f_{\text {ice }}$ with RHi to evaluate ice formation rates (see Sect. 6). Clearly, 

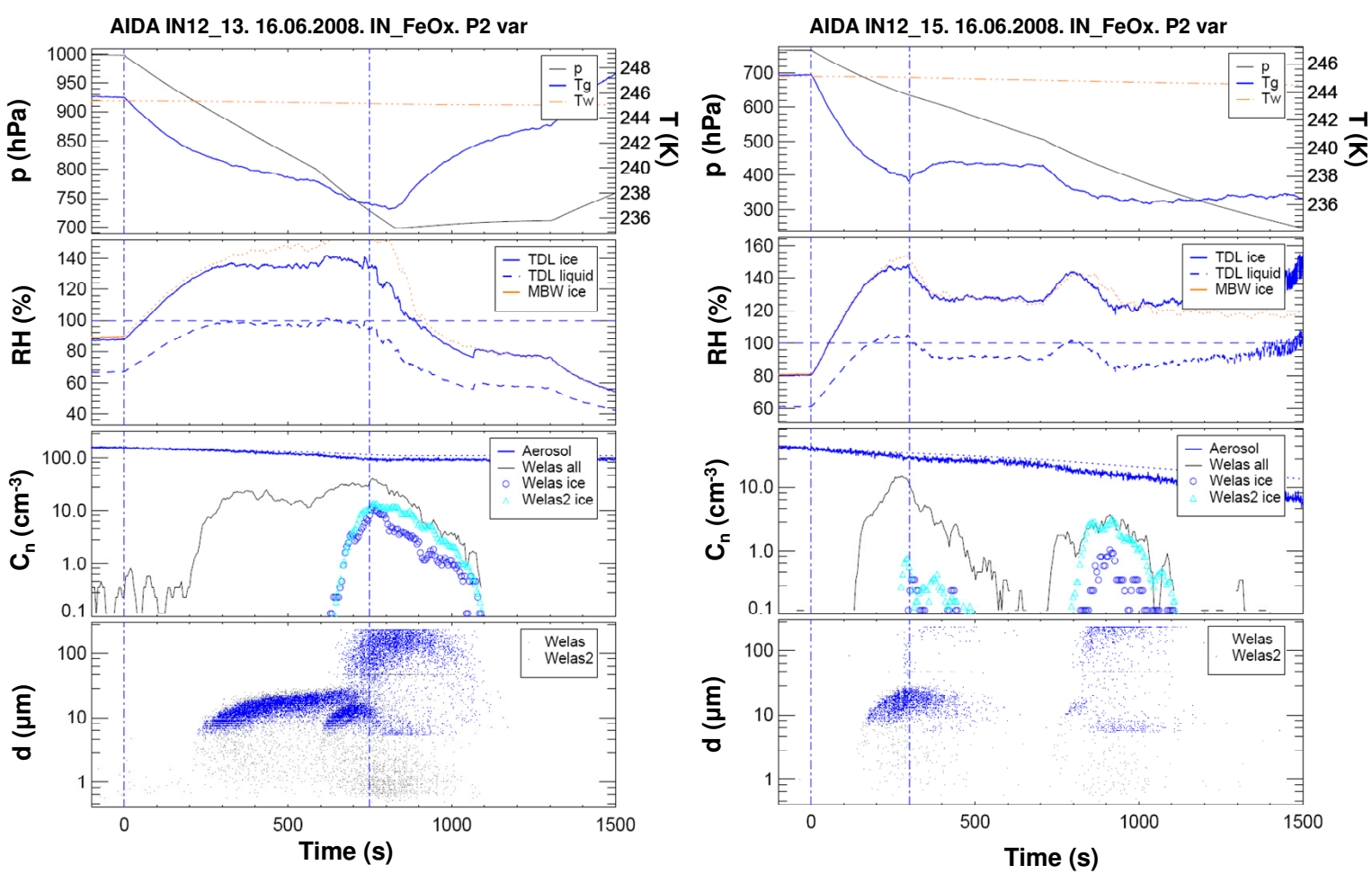

Fig. 8. Nucleation data sets (IN12,\#13 - left and \#15 - right) for the $\mathrm{Fe}_{2} \mathrm{O}_{3}$ nanoparticles generated in-situ at the chamber with $T_{i} \sim 246 \mathrm{~K}$. The left-hand side set was obtained with the initial air pressure at the "normal" level whereas the right-hand side data was from a lower initial air pressure run in the chamber.

even after discounting these effects, the $9 \%$ activation level of a sub- $80 \mathrm{~nm}$ particle size distribution at $182 \mathrm{~K}$ suggests that aerosols of such dimensions and compositions have the potential to nucleate ice at sufficient supersaturation levels in the atmosphere.

\subsection{Particle structure}

Finally, Table 1 - section $\mathrm{C}$ illustrates differences between the three structural forms of $\mathrm{Fe}_{2} \mathrm{O}_{3}$ aerosol used i.e. the laboratory-generated amorphous powder, the commercial crystalline powder and the synthesised pseudocubic form, for the same value of $T_{i}$. At $192-193 \mathrm{~K}$, the preferred form of ice is predicted to be cubic $\left(\mathrm{I}_{c}\right)$. Data comparison shows that the pseudocubic form of $\mathrm{Fe}_{2} \mathrm{O}_{3}$ has a significantly higher $f_{\text {ice-max }}$ value than either the amorphous or non-cubic crystalline forms. However, this observation must be qualified by the fact that the pseudocubic particles were much larger in size and so it may be that both size and structural factors are responsible for the observed differences in nucleating ability. The non-cubic aerosol particles showed similar nucleating efficiencies although the larger modal size of the crystalline sample could mean that, once again, size effects were the primary reason for differences in the nucleation data, rather than structural considerations.

\section{Data analysis}

For quantitative analysis of the chamber ice nucleation data, we have adopted two common approaches (see Pruppacher and Klett, 1997): (i) the stochastic (classical) determination of the contact angle $(\theta)$ between the smoke particle and growing ice embryo, which inherently assumes that $\theta$ is the same for any particle of the same size and composition, and (ii) a more recently developed approach based upon the "singular hypothesis" which determines a particle-specific parameter known as the ice-active surface site density $\left(n_{s}\right)$.

Whilst the classical approach provides a comparison with $\theta$ values assumed in previous theoretical studies of heterogeneous ice nucleation by MSPs (e.g. Keesee, 1989; Rapp and Thomas, 2006), it should be noted that the values derived from the observed threshold nucleation data and measured aerosol distributions can only be taken as representative of the efficiency of the most active sites on the particles. In practice, there is likely to be a distribution of contact angles in an aerosol population as a result of variations of the surface sites available for ice nucleation. Consequently, the second approach, which specifically treats such inherent particle site variability, is more rigorous, but due to its relatively recent development, has a smaller literature database for comparison of evaluated $n_{s}$ values. 

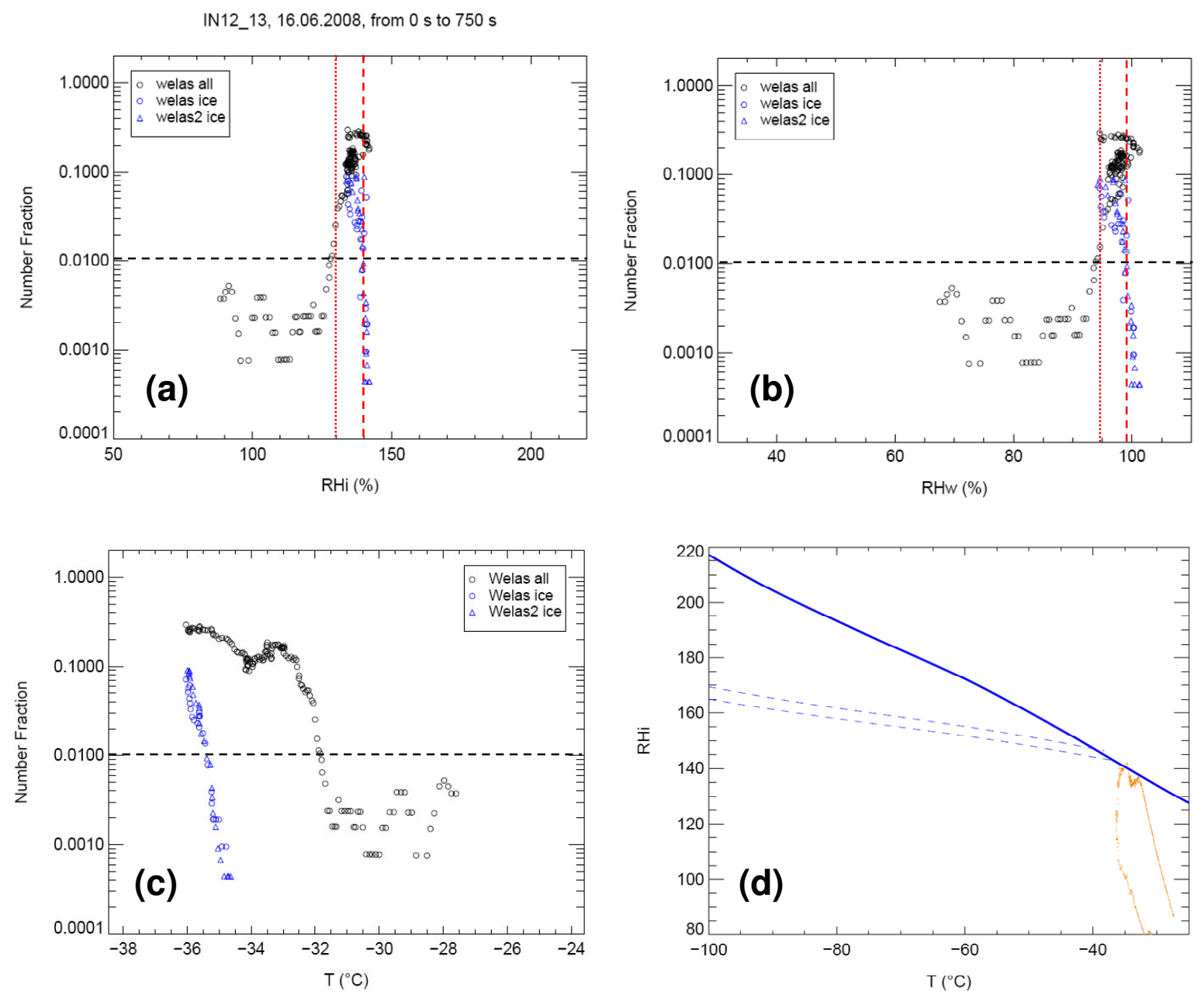

Fig. 9. Summary plots for the ice nucleation experiment (IN12, \#13) on in-situ-generated $\mathrm{Fe}_{2} \mathrm{O}_{3}$ nanoparticles at $T_{i} \sim 246 \mathrm{~K}$ (calculated from left-hand data set in Fig. 8). Panel (a) shows the number fraction $(f)$ of detected ice particles (blue symbols) and total fraction (black symbols) i.e. droplets plus ice, as a function of RHi, panel (b), $f$ versus RHw, panel (c), $f$ versus $T$, and panel (d) RHi versus $T$. Red lines mark positions of critical RH values (dot: droplet detection, dash: ice detection) and the dashed black line indicates the defined threshold value $\left(f_{\text {ice }-\mathrm{t}}\right)$.

\subsection{Classical theory: contact angle determination}

From classical heterogeneous nucleation theory, the critical parameter which defines the efficiency of a particular material as an ice-nucleating substance is the contact angle $(\theta)$, which is determined from the contact parameter $(m=$ cosine $\theta$ ). For a flat or a curved surface (i.e. particle), $m$ can be estimated from experimental measurements of the minimum saturation ratio $\left(s_{\text {crit }}\right)$ at which ice nucleation is observed for a given temperature. Nucleation efficiency increases as $m \rightarrow 1$ or $\theta \rightarrow 0^{\circ}$.

The recent paper by Trainer et al. (2009) reported such data for a silicon wafer at temperatures down to $150 \mathrm{~K}$ and determined a temperature-dependent contact parameter using the classical equations from Pruppacher and Klett (1997). Following this method, we have used the AIDA data for the particle samples described earlier to ascertain the values of $m$ (and hence $\theta$ ) at the temperatures used in the respective nucleation runs as indicated in Table 1.

The surface nucleation rate $\left(J: \mathrm{cm}^{-2} \mathrm{~s}^{-1}\right)$ in each chamber run, required for determination of the matching function $f(m, x)$ with respect to curved (particle) surfaces (see equation 9 of Trainer et al., 2009), and hence $\theta$, were calculated following the procedure outlined in Sect. 3.2 (Eq. 3-5) of the paper by Möhler et al. (2006). For the specific particle type/chamber temperature, the $J$ value is obtained from the ratio of the rate of ice crystal formation $\left(\mathrm{d} n_{\text {ice }} / \mathrm{d} t: \mathrm{cm}^{-3} \mathrm{~s}^{-1}\right)$, calculated from the observed threshold RHi value at a given temperature, to the particle surface area $\left(\mathrm{cm}^{2} \mathrm{~cm}^{-3}\right)$, determined from the measured initial particle distribution.

Figure 12 shows the temperature-dependent contact angle values determined as described for the three $\mathrm{Fe}_{2} \mathrm{O}_{3}$ particle 
IN12_17, 17.06.2008, from $0 \mathrm{~s}$ to $1050 \mathrm{~s}$
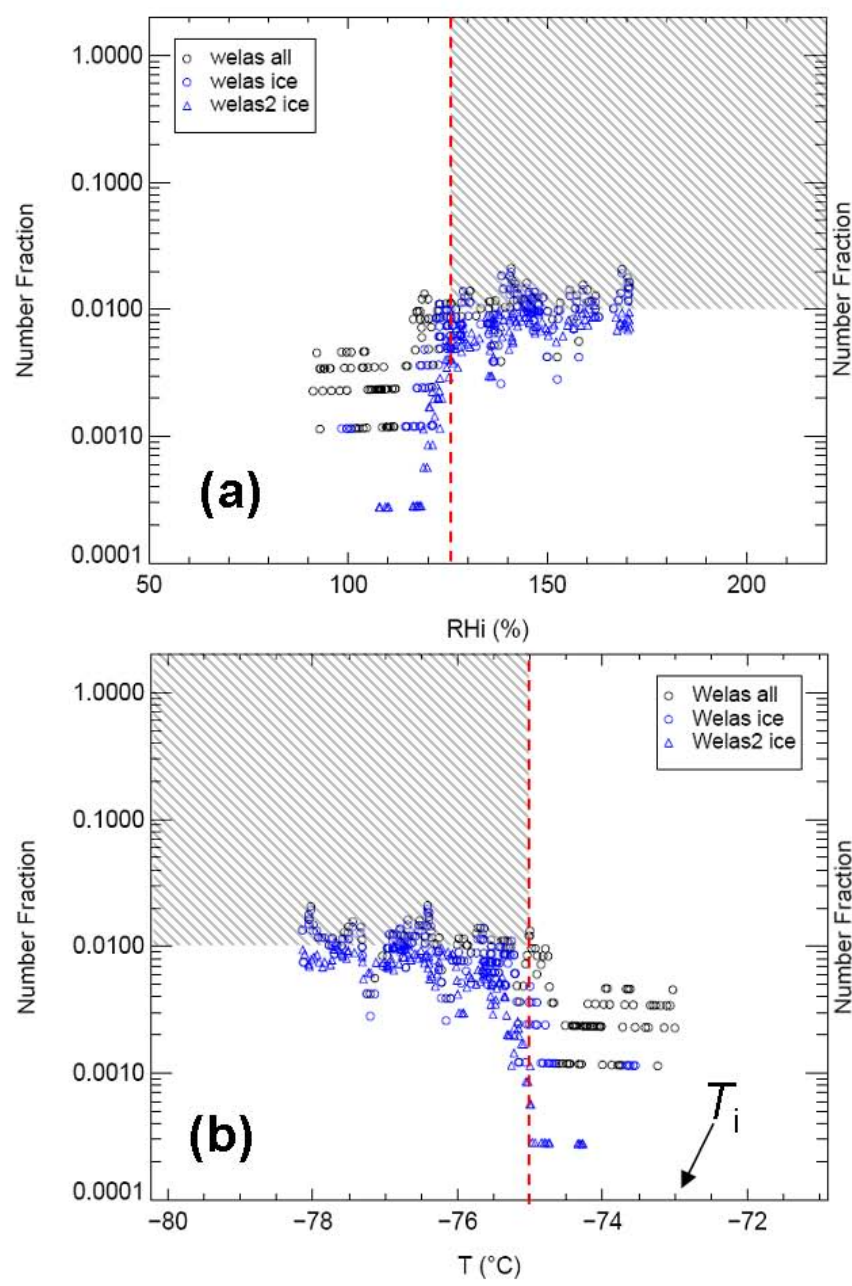

IN12_09, 12.06.2008, from $0 \mathrm{~s}$ to $1800 \mathrm{~s}$
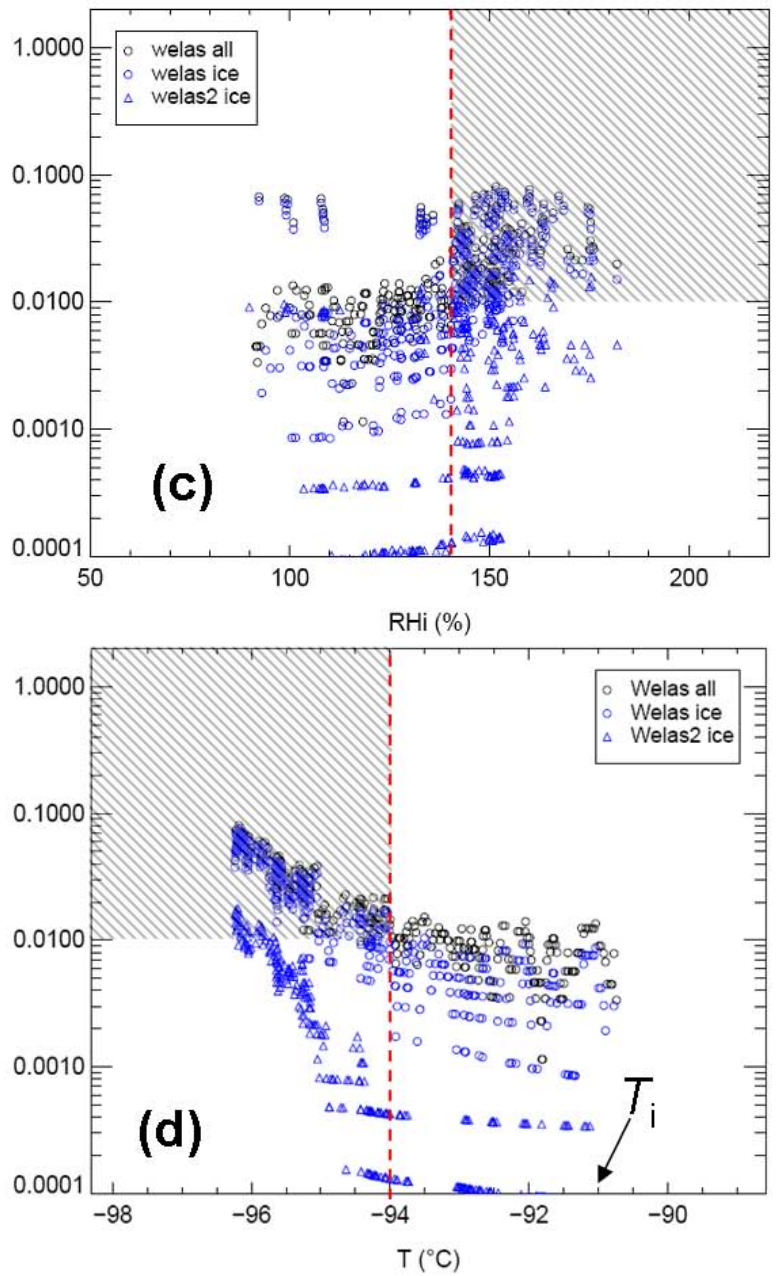

Fig. 10. Calculated ice number fraction data (IN12, \#17 - left and \#9 - right) for nucleation experiments with $\mathrm{Fe}_{2} \mathrm{O}_{3}$ nanoparticles with $T_{i}=200 \mathrm{~K}$ (left) and $182 \mathrm{~K}$ (right). Top panels show $f_{\text {ice }}$ as a function of RHi; bottom panels as a function of chamber air temperature ( $T$ ). Red dashed lines indicate critical RHi and $T$ values for the respective experiments for which $f_{\text {ice }}>0.01\left(f_{\text {ice }-t}\right)$. Data points within the hatched areas therefore correspond to conditions for which $f_{\text {ice- }}$ is exceeded.

samples as indicated. The data shows clearly that the contact angle (as defined schematically in the figure) increases with decreasing temperature for all samples. Analogous behaviour was observed by Trainer et al. (2009) for a planar silicon surface. They reported a much sharper rise in $\theta$, particularly for $T<180 \mathrm{~K}$, which of course we are not able to verify with our samples as these low temperatures are not achievable in the AIDA chamber. However, the angles for the iron oxide particles are significantly lower than those for the silicon surface. For example, at $182 \mathrm{~K}$, Trainer et al. (2009) report $m=0.896\left(\theta=26.4^{\circ}\right)$ compared with that of $\sim 10.5^{\circ}$ for the nanoparticles generated in situ at the chamber. This most likely reflects the more hydrophilic nature of the metal oxide compared with pure silicon. It is noticeable that at $T>210 \mathrm{~K}$, the calculated contact angles are very similar $\left(5-7^{\circ}\right)$ for all three samples, whilst at lower temperatures the particles generated in situ display a smaller temperature dependence and so seem to be the most efficient nucleating species at $T<200 \mathrm{~K}$. The larger contact angles found for the powder samples in Fig. 12 are most probably an indication of a greater hindrance to the formation of stable ice embryos at the surfaces of the more aggregated particle samples. In addition, all values lie well below the horizontal line at $\theta=18.2^{\circ}(m=0.95)$, the "nominal" value usually assumed in modelling of NLC formation (Rapp and Thomas, 2006), although at summer mesopause temperatures below $150 \mathrm{~K}$ it is probable that the contact angles for iron oxide aerosol will approach or possibly exceed this value, due to the likelihood of non-hexagonal or metastable (cubic or amorphous) ice formation directly from the vapour phase being increasingly 
IN12_03, 10.06.2008, from $0 \mathrm{~s}$ to $1000 \mathrm{~s}$
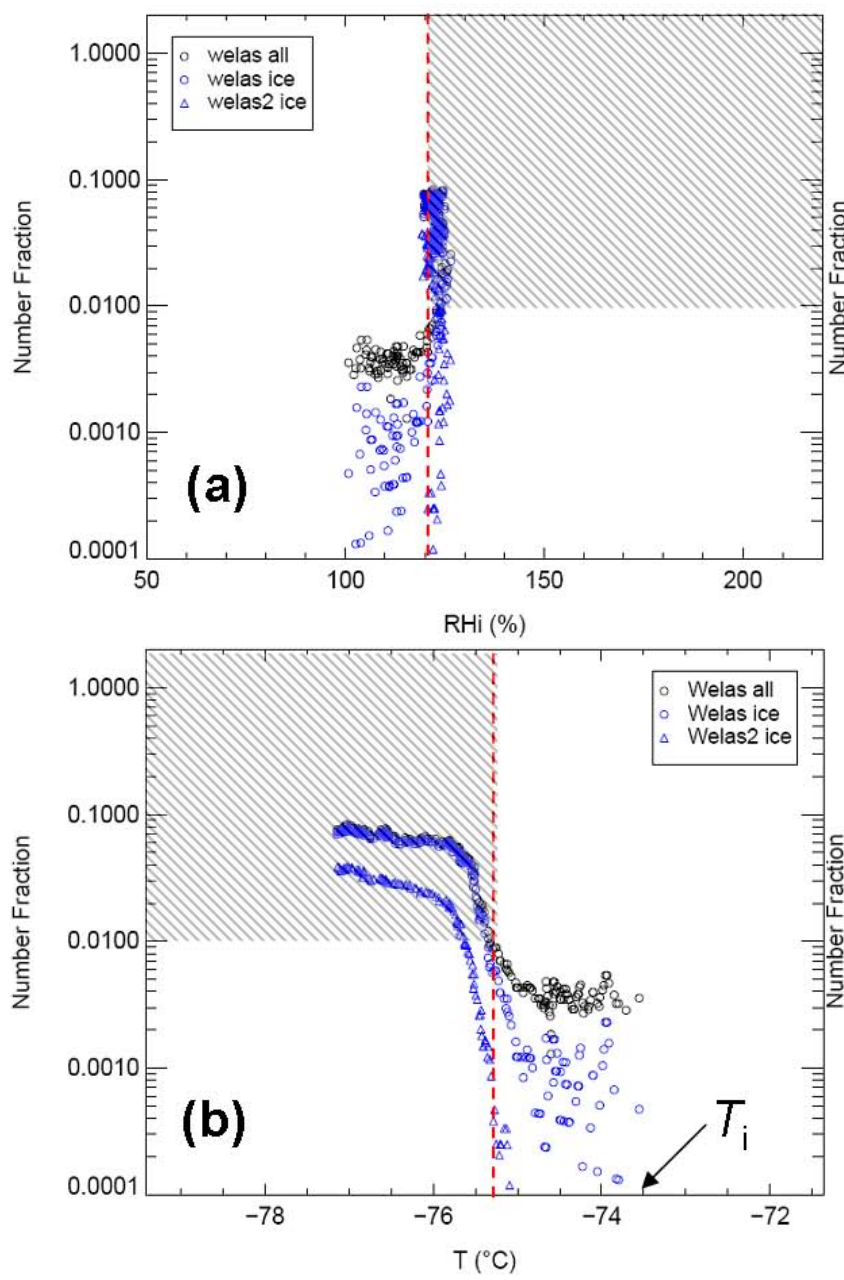

IN12_21, 18.06.2008, from $0 \mathrm{~s}$ to $900 \mathrm{~s}$
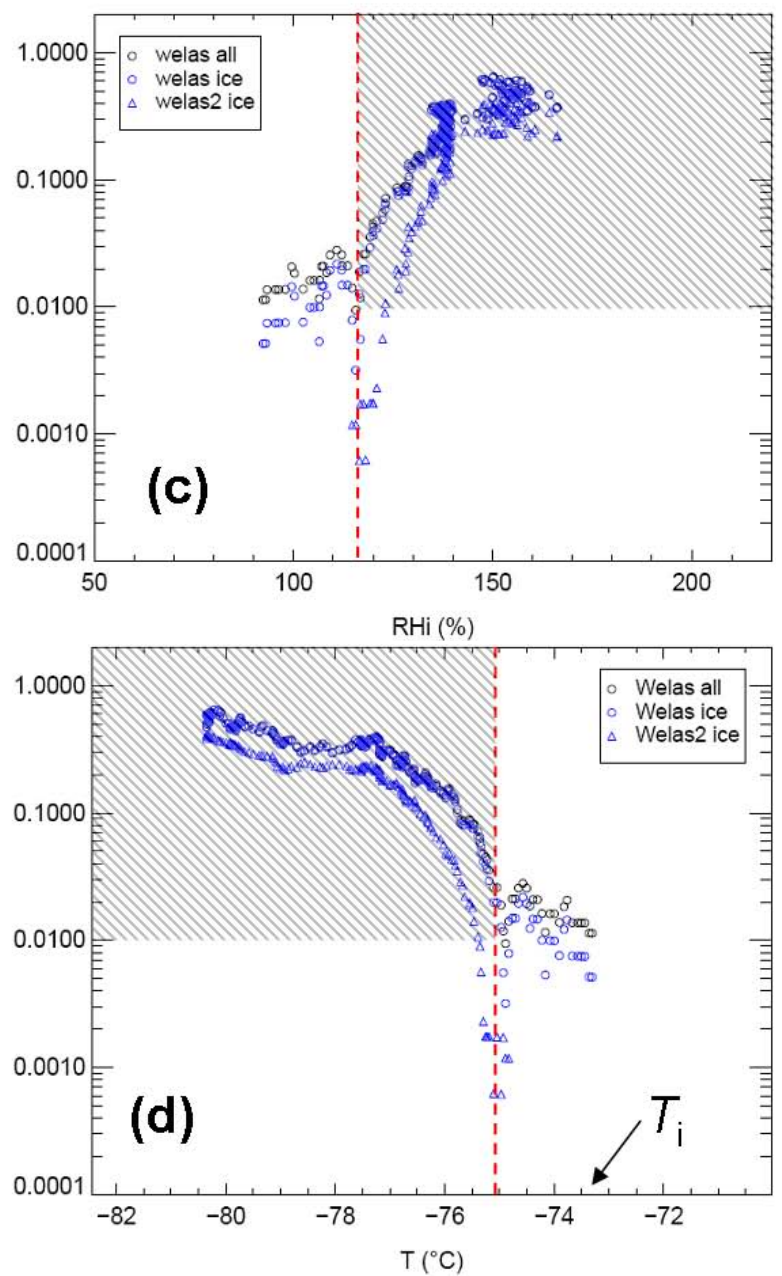

Fig. 11. Calculated ice number fraction data $(I N 12$, \#03 - left and \#21 - right) for nucleation experiments with $\mathrm{MgO}$ powder (left) and $\mathrm{SiO} 2$ powder (right) at $T_{i} \sim 200 \mathrm{~K}$. Top panels show $f_{\text {ice }}$ as a function of RHi; bottom panels as a function of chamber air temperature $(T)$. Red dashed lines indicate critical RHi and $T$ values for the respective experiments for which $f_{\text {ice }}>0.01\left(f_{\text {ice }-\mathrm{t}}\right)$. Data points within the hatched areas therefore correspond to conditions for which $f_{\text {ice }-\mathrm{t}}$ is exceeded.

favoured under such conditions (Murphy and Koop, 2005; Shilling et al., 2006).

Of course, particles larger than the modal size will most probably tend to nucleate ice first at somewhat lower $s_{\text {crit }}$ values than for the modal size particle, but as these are at much lower number concentrations, they probably lead to the formation of ice crystal numbers below the threshold levels. For example, for the IN12_\#9 run (in situ generated particles, $T_{i}=182 \mathrm{~K}$ and $\left.s_{\text {crit }}=1.4\right)$, at the same contact angle of $10.5^{\circ}$ ( $m \sim 0.983$ ) determined for the modal particle size (from the surface area distribution) of $\sim 27 \mathrm{~nm}$, an $s_{\text {crit }}$ value of 1.33 is predicted at $40 \mathrm{~nm}$.

For the $\mathrm{SiO}_{2}$ and $\mathrm{MgO}$ samples at $200 \mathrm{~K}$, the contact angles are $10.2^{\circ}$ and $11.4^{\circ}$ respectively.

\subsection{Singular hypothesis method}

\subsubsection{Analysis}

For a given aerosol type/chamber temperature experiment, a $\log$ normal fit to the measured size distribution of initial aerosol (prior to the start of the nucleation experiment) was used to define the available surface area available for nucleation. Then, the measured ice crystal number concentration from the WELAS OPC, and the measured RH from the TDL and temperature probes were used to determine the number of ice active surface sites that become active at a set RH. This is equivalent to the "singular hypothesis" i.e. the surface of each particle is assumed to have a characteristic active site density as a function of the driving nucleation variable. Such 


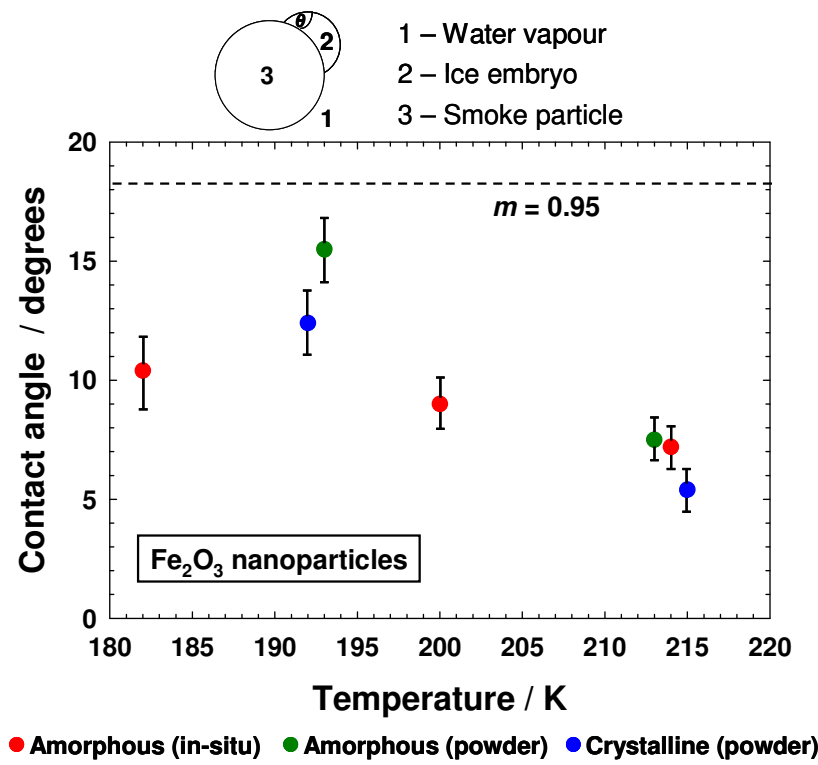

Fig. 12. Variation in estimated contact angle $(\theta)$ values with temperature for the three iron oxide particle samples indicated. The schematic at the top of the figure is used to illustrate the definition of $\theta$ with respect to heterogeneous ice nucleation on a particle.

a treatment is analogous to the theory discussed in Connolly et al. (2009) with respect to the heterogeneous freezing mode (for which temperature is the critical parameter), but adapted for the scenario of heterogeneous deposition nucleation (see Sect. 3.3.2 of Connolly et al., 2009), for which RH (or saturation ratio) is the parameter of interest. To date, this approach has only been applied to heterogeneous ice nucleation at warm cloud temperatures for micron-sized terrestrial dust samples.

Figure 13 provides a schematic explanation of the analytical approach taken using a representative particle nucleation data set. It is important to note that in this analysis we assume that the area provided by the smoke particles is given by the equivalent spherical surface area.

Analysis was performed for experiments that used the commercial (crystalline) sample, the prepared (amorphous) laboratory sample and the in situ generated amorphous particles of iron oxide composition. Figure 14 shows the derived values of ice-active surface site density $\left(n_{s}\right)$ for the iron oxide particles at two chamber temperatures ( $\sim 190$ and $215 \mathrm{~K})$ for the experiments as indicated in the left-hand plot.

These experiments clearly show that heterogeneous deposition nucleation is more efficient at the higher temperature, indicated by the higher values of $n_{s}$ for lower values of $\mathrm{RH}_{i}$. This can be understood by classical nucleation theory which predicts that the energy of germ formation is inversely proportional to temperature (as predicted by Boltzmann statistics) and also inversely proportional to the natural logarithm of the supersaturation (a result of the surface energy of germ

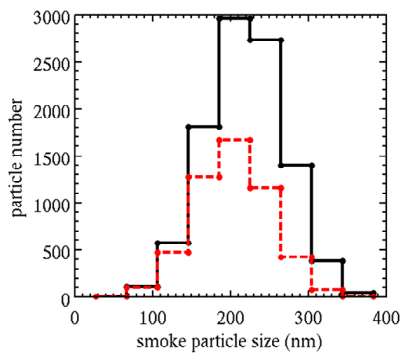

$\frac{\Delta N_{i c e}}{\sum_{j} N_{j, \text { smoke }} A_{j, \text { smoke }}}=k\left(s_{i c e}\right) \Delta s_{\text {ice }}$

$k=\frac{d n_{s}}{d s_{i c e}}$
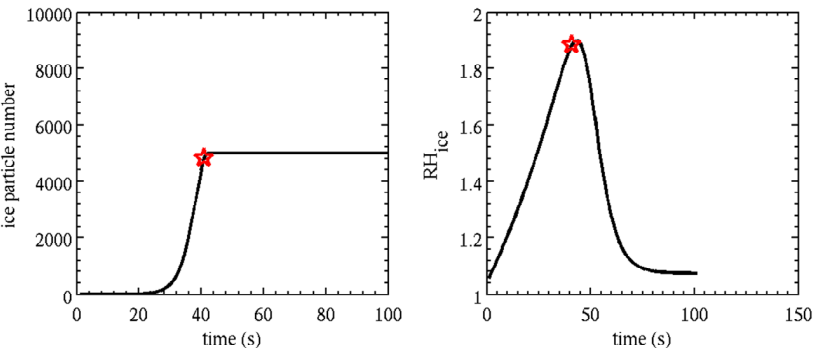

Fig. 13. Illustration of how the ice nucleation data were analysed. Top left: black shows the initial smoke particle size distribution, red shows the smoke distribution after nucleation has occured. Note that the largest particles are depleted first as these have the larger surface area for nucleation to occur. Bottom left: shows the temporal variation of measured ice particle number concentration with the star indicating the ice concentration that corresponds to the point in time where the smoke distribution is as in the red histogram. Bottom right: shows the variation in RHi with chamber expansion time. Note that no nucleation occurs once the peak RH has occurred. This data is used to define the ice active surface site density per saturation interval $\left(\mathrm{k}\left(\mathrm{s}_{\mathrm{ice}}\right)\right)$ by dividing the change in ice particle number by the total surface area available for nucleation $\left(\Sigma N_{j, \text { smoke }} \mathrm{A}_{j \text {, smoke }}\right.$, where $\mathrm{N}$ and $\mathrm{A}$ are the number and surface area of smoke particles in size bin $j$ ). This provi This provides a function that describes the number of ice active sites per unit area of aerosol at saturation ratio $s_{\text {ice. }}$

formation). Normally at warmer temperatures the supersaturation effect is dominant over the temperature fluctuation effect and we observe that nucleation is more efficient at the ice supersaturation. However, at very cold temperatures the molecular fluctuations associated with the heat of the substance become important and, in principle, the opposite behaviour may be observed. It is interesting to note that there is no significant difference between the IN activity of the crystalline samples vs the amorphous samples when the surface area is taken into account (e.g. comparing IN experiments 59 with 61).

The function fitted to the data at $190 \mathrm{~K}, n_{s} 10^{\left(3.33 \cdot s_{\text {ice }}\right)+8.16}$ (green line - bottom panel), was used to model ice formation under different conditions i.e. updraft, initial temperature, different mode radius of particles. 

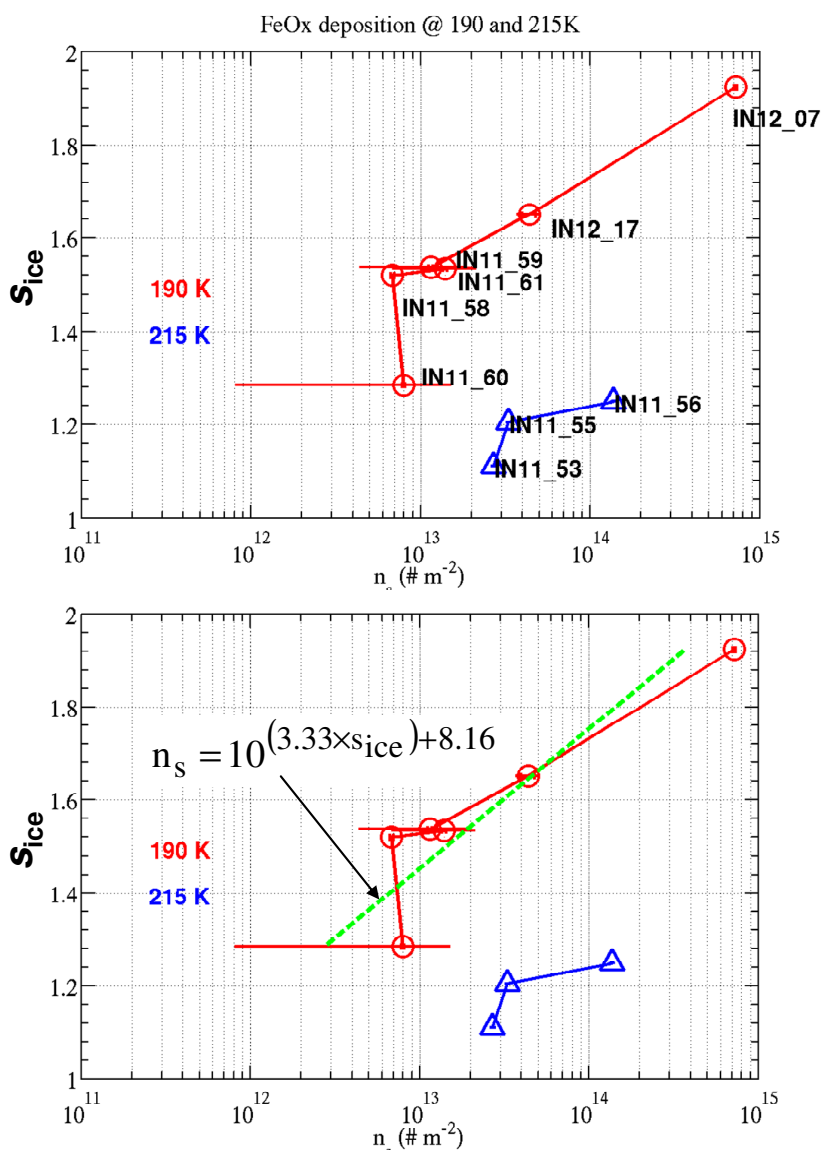

Fig. 14. Top: shows the calculated number of active sites per unit area of material that become active at the given $s_{\text {ice }}$ for the iron oxide aerosol experiments as indicated. Errorbars denote 5 and 95 percentiles assuming that the Poisson distribution describes the uncertainty. Bottom: for the colder experiments, a curve (green line) was fitted through the data using the least squares method. The equation for this fit was used in the modelling studies.

\subsubsection{Modelling}

The model used is a cloud parcel bin model which includes treatments of both ice and liquid microphysics, and the role of aerosol surfaces (see appendix of Connolly et al., 2009 for details). The fitted RHi vs $n_{s}$ data derived in the previous section with respect to iron oxide nanoparticles were used along with log-normally distributed particle size distributions to predict the activated fraction of the particles and the corresponding peak saturation ratio $\left(s_{\text {ice }}\right)$ under conditions appropriate for the upper atmosphere. Model simulations were started at $180 \mathrm{~K}$ at $s_{\text {ice }}=0.95$ with a smoke particle concentration of $100 \mathrm{~cm}^{-3}$ (in line with the recent 2-D \& 3-D modelling studies of Megner et al., 2008a \& b and Bardeen et al., 2008).

For vertical motions we adopted a gravity wave scheme that results in a peak cooling rate of 0.01 to $0.1 \mathrm{~K} \mathrm{~s}^{-1}$ (or equivalently 0.1 to $1 \mathrm{~m} \mathrm{~s}^{-1}$ assuming adiabatic expansion).
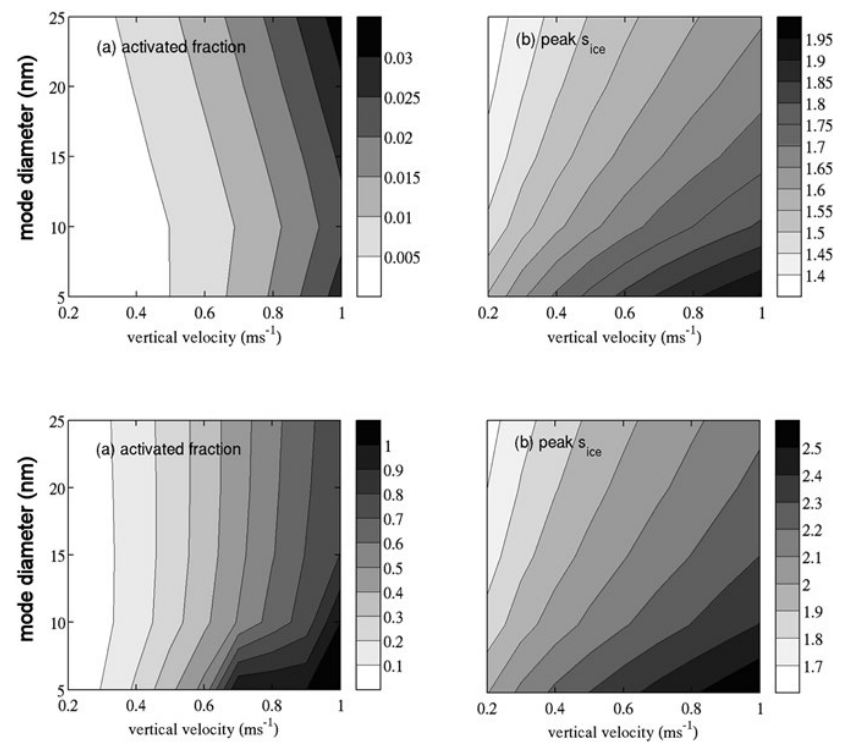

Fig. 15. Simulations with a cloud parcel model to infer the activated fraction of particles as IN (chamber data for iron oxide nanoparticles were used in the model runs). Top panels: left shows the activated fraction for different updraught velocities and initial mode diameter of the smoke particles and right shows the peak supersaturation achieved in the simulation (simulations assume an ice deposition coefficient of 1.0). Bottom panels: As in top panels but simulations assumed an ice deposition coefficient of 0.1 . Note that in these simulations the activated fraction is significantly higher.

Gravity waves of this order are fairly typical in the upper mesosphere (e.g. Hoppe and Fritts, 1995). Although the diurnal and semidiurnal tides result in weaker vertical motions, the range of gravity wave cooling rates was chosen for an upper boundary on the cooling rate. Results from the model are shown in Fig. 15.

Note that if we use a deposition (mass accommodation) coefficient $\left(\alpha_{D}\right)$ of 1.0 for water vapour uptake on ice we are unable to activate sufficiently high fractions of smoke particles as IN since the water vapour is depleted quickly by the growing ice crystals (Fig. 15, top panels). In order to nucleate sufficiently high numbers of smoke particles as IN, the super-saturation must build up to high enough values. For the range of values in our simulations this can be achieved by reducing the deposition coefficient for ice to around 0.1 (Fig. 15, bottom panels). It is interesting to note that higher activated fractions occur for the smaller mode diameter. This is because in this regime the deposition coefficient has the largest sensitivity for small particles.

In order to explain growth rates of small ice crystals using the standard depositional growth model, values of $\alpha_{D}$ much less than unity were inferred from the laboratory measurements of Magee et al. (2006), while a value of 0.1 is consistent with literature values tabulated in Choularton and Latham (1977) for the appropriate temperature range. 


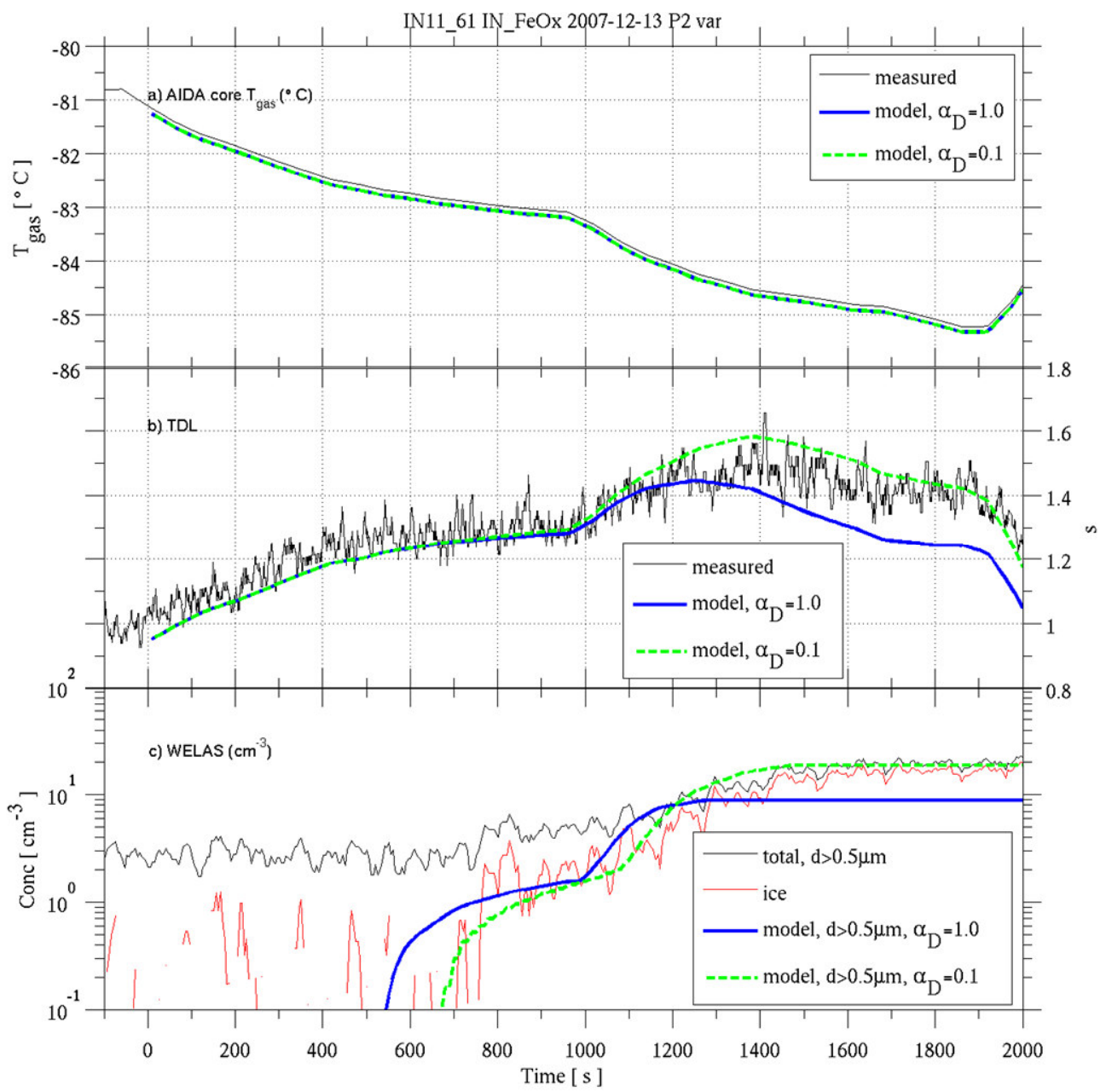

Fig. 16. Observations and model simulation of experiment $I N 11$, \#61 (commercial $\mathrm{Fe}_{2} \mathrm{O}_{3}$ ). Note that temperature and pressure were constrained in the model to the observations as was the total water (condensed plus vapour) in the simulation (as measured by the chilled mirror hygrometer). The free variables then are the ice water concentration and mass (and thus the water vapour supersaturation) calculated by the model. We note that for a deposition coefficient of 1.0 the ice crystals grow too fast and deplete the available water vapour so that ice concentrations in the model are too low. Better agreement is found using a deposition coefficient of 0.1 where the simulated water vapour supersaturation and the ice crystal number concentration give good agreement to observations. Initial smoke particle size distribution parameters were: $N_{L}=55 \mathrm{~g}^{-1}$ (of air), $\ln (\sigma)=0.4762$ and $D_{m}=0.26 \mu \mathrm{m}$.

Figure 16 shows the results of model simulations of the temporal evolution of ice crystal number (bottom panel) from a representative experiment (IN11, \#61; crystalline $\mathrm{Fe}_{2} \mathrm{O}_{3}$ particles; $T_{i} \sim 196 \mathrm{~K}$ ), assuming $\alpha_{D}$ values of 1.0 and 0.1 . In this experiment and others (not shown) the best agreement between observations and modelling is found when using a deposition coefficient of 0.1 .

\section{Atmospheric implications}

The reported chamber ice nucleation results at temperatures below $230 \mathrm{~K}$ for amorphous iron oxide nanoparticles/aggregates and silicon- and magnesium oxide powders with particle dimensions ranging from $\sim 10-300 \mathrm{~nm}$ suggest that these refractory aerosol species are likely to play an important role in ice cloud/PSC formation in the upper troposphere/stratosphere. The inherently alkaline nature of metal oxide particles will certainly favour the uptake and condensation of sulphuric acid onto particle surfaces within the Junge layer, and thus lead to a role in the formation of PSCs (Turco et al., 1981).

In terms of ice cloud formation in the mesosphere, studying the heterogeneous nucleating abilities of meteoric smoke particles smaller than $10 \mathrm{~nm}$ diameter (typically $0.5-2 \mathrm{~nm}$ ) and at temperatures below $150 \mathrm{~K}$ currently remains beyond the experimental capabilities of large volume chambers and particle detection instruments. Consequently, any detailed extrapolation of our nucleation studies to the mesosphere is not possible, but some general comments can be made. For 
example, the classic 1-D model prediction (Hunten et al., 1980) of smoke particle concentrations of a few thousand per $\mathrm{cm}^{3}$ at NLC-forming altitudes $(80-90 \mathrm{~km})$ would require ice activation levels of greater than $\sim 5 \%$ to explain typical ice crystal numbers of around $100 \mathrm{~cm}^{-3}$ in these clouds as indicated by lidar studies (e.g. von Cossart et al., 1999). However, more recent 2-D and 3-D modelling treatments of the growth and transport of smoke particles (Megner et al., 2008a; Bardeen et al., 2008) suggest that the concentrations of smoke particles are much lower $\left(<200 \mathrm{~cm}^{-3}\right)$ at the summer mesopause because of rapid meridional transport to lower latitudes. Clearly at these levels, it becomes increasingly difficult to envisage a major role for MSPs in heterogeneous ice nucleation, even if activation levels approached $100 \%$. However, there are two ways in which MSPs could still act as efficient IN. First, if a significant fraction of the MSP population attains a steady-state charge within the plasma which exists in the upper atmosphere (see Rapp, 2009), then certain critical constraints (primarily the minimum particle size) with respect to ice nucleation will be removed (Megner et al., 2008b, Gumbel and Megner, 2009), thus increasing the likely activation levels. Indeed, higher levels would be needed to account for the numbers $\left(>1000 \mathrm{~cm}^{-3}\right)$ of smaller charged ice particles (inferred from radar detection) which give rise to the phenomenon of polar mesosphere summer echoes (PMSE) in this altitude region (Rapp and Lübken, 2004). Second, individual molecules containing meteoric metals (e.g. $\mathrm{NaHCO}_{3}$, $\mathrm{FeSiO}_{3}$ ) have very high electric dipole moments $(>8 \mathrm{D})$, which result in significantly lower binding energies for polar $\mathrm{H}_{2} \mathrm{O}$ molecules (Plane, 2000). With these considerations in mind, it seems most likely that MSPs nucleate ice particles in the upper mesosphere alongside other mechanisms, including ion-induced (Keesee, 1989; Gumbel and Witt, 2002) and homogeneous nucleation (Murray and Jensen, 2010; Zasetsky et al., 2009).

\section{Conclusions}

All refractory particles $\left(\mathrm{Fe}_{2} \mathrm{O}_{3}, \mathrm{SiO}_{2}\right.$ and $\left.\mathrm{MgO}\right)$ studied at the AIDA nucleation chamber were observed to nucleate ice to a significant degree under conditions of super-saturation (with respect to ice), between $182 \mathrm{~K}$ and $215 \mathrm{~K}$. The powder samples in all cases produced ice number fractions $\left(f_{\text {ice }}\right)$ of $\geq 0.08$ for temperatures of $200 \mathrm{~K}$ or below, with the crystalline (commercial) iron oxide and amorphous silica samples showing the highest (maximum) values of 0.5 at $192 \mathrm{~K}$ and 0.5 at $200 \mathrm{~K}$ respectively, and the lowest threshold RHi values (defined as the level at which $f_{\text {ice }}>1 \%$ ) of $125 \%$ and $118 \%$ respectively. $\mathrm{MgO}$ particles (with cubic structure) showed a significantly lower maximum $f_{\text {ice }}$ of $0.08\left(\mathrm{RHi}_{\text {thresh }}=120 \%\right)$ at $200 \mathrm{~K}$, whilst the pseudo-cubic form of $\mathrm{Fe}_{2} \mathrm{O}_{3}$ produced a much higher ice fraction of 0.8 $\left(\mathrm{RHi}_{\text {thresh }}=130 \%\right)$, although this observation must be coun- tered with the fact that these particles were significantly larger (edge-length of 500-600 nm) than the particles from the powder samples (poly-disperse with modal sizes of 100 $-250 \mathrm{~nm}$ ).

The $\mathrm{Fe}_{2} \mathrm{O}_{3}$ nanoparticles generated in situ in a photochemical reactor adjacent to the nucleation chamber were much smaller (typical modal size $\sim 30 \mathrm{~nm}$ ) and were still observed to initiate ice crystal formation $\left(\mathrm{RHi}_{\text {thresh }}=140 \%\right.$ at $\left.182 \mathrm{~K}\right)$ with $f_{\text {ice }-\max }=0.09$. Contact angle values determined for these particles (e.g. $10.5^{\circ}$ at $182 \mathrm{~K}$ ) indicate that amorphous iron oxide nanoparticles are relatively efficient nucleating surfaces when compared with recently reported data for pure silicon. Direct comparison of determined contact angles of the three oxide nanoparticle types at $200 \mathrm{~K}$ indicate a nucleation efficiency order of $\mathrm{Fe}_{2} \mathrm{O}_{3}>\mathrm{SiO}_{2}>\mathrm{MgO}$.

Modelling of the low temperature $(<200 \mathrm{~K})$ nucleation data for iron oxide nanoparticles using a fitted function obtained from evaluated ice-active surface site density values, indicates a deposition coefficient of 0.1 for water vapour onto nucleated ice crystals for conditions relevant to the upper atmosphere i.e. significantly smaller than the value of 1 typically assumed in NLC model studies to date (see Rapp and Thomas, 2006).

The nucleation runs conducted at $246 \mathrm{~K}$ and with $\mathrm{RHw}$ $\rightarrow 100 \%$ (see Figs. 8 and 9) clearly indicate a different mechanism characterised by initial droplet formation and subsequent freezing to form ice crystals, as observed previously at the AIDA chamber in the case of Asian desert dust (Cotton et al., 2007). This indicates that under such conditions, the particles are acting as $\mathrm{CN}$ rather than IN and the droplets only freeze at or close to the homogeneous limit. The conclusion is that $\mathrm{Fe}_{2} \mathrm{O}_{3}$ particles in either crystalline or amorphous forms will not initiate ice nucleation in tropospheric mixed phase clouds.

Acknowledgements. This work was supported by funding from the UK Natural Environment Research Council (NERC grant NE/E005659/1). OM acknowledges funding from the research program ATMO of the Helmholtz Association. BJM acknowledges NERC for a fellowship (grant NE/D009308/1). We are very grateful to the AIDA chamber technicians for their efforts during the two campaign periods.

Edited by: J. Curtius

\section{References}

Archuleta, C. M., DeMott, P. J., and Kreidenweis, S. M.: Ice nucleation by surrogates for atmospheric mineral dust/sulphate particles at cirrus temperatures, Atmos. Chem. Phys., 5, 2617-2634, 2005, http://www.atmos-chem-phys.net/5/2617/2005/.

Baragiola, R. A.: Water ice on outer solar system surfaces: basic properties and radiation effects, Planet Space Sci., 51, 953-961, 2003.

Bardeen, C. G., Toon, O. B., Jensen, E. J., Marsh, D. R., and Harvey, V. L.: Numerical simulations of the three-dimensional distribu- 
tion of meteoric dust in the mesosphere and upper stratosphere, J. Geophys. Res., 113, D17202, doi:10.1029/2007JD009515, 2008.

Benz, S., Megahed, K., Möhler, O., Saathoff, H., Wagner, R., and Schurath, U.: T-dependent rate measurements of homogeneous ice nucleation in cloud droplets using a large atmospheric simulation chamber, J. Photochem. Photobiol. A, 176, 208-217, 2005.

Biermann, U. M., Presper, T., Koop, T., Mößinger, J., Crutzen, P. J. and Peter, Th.: The unsuitability of meteoritic and other nuclei for polar stratospheric cloud freezing, Geophys. Res. Lett., 23, 1693-1696, 1996.

Bigg, E. K. and Giutronich, J.: Ice nucleating properties of meteoritic material, J. Atmos. Sci., 24, 46-49, 1967

Bogdan, A. and Kulmala, M.: Aerosol silica as a possible candidate for the heterogeneous formation of nitric acid hydrates in the stratosphere, Geophys. Res. Lett., 26, 1433-1436, 1999.

Bogdan, A.: Fumed silica as a host for study of large surface-tovolume ratio problems in finely divided aqueous systems: Implications for the atmosphere, in: Adsorption on Silica Surfaces, edited by: Papirer, E., Marcel Decker Inc., New York, USA, 689739, 2000.

Choularton, T. W. and Latham, J.: Measurements of the deposition coefficient for ice, and its application to cirrus seeding, Q. J. Roy. Meteorol. Soc., 103, 307-318, 1977.

Connolly, P. J., Möhler, O., Field, P. R., Saathoff, H., Burgess, R., Choularton, T., and Gallagher, M.: Studies of heterogeneous freezing by three different desert dust samples, Atmos. Chem. Phys., 9, 2805-2824, 2009, http://www.atmos-chem-phys.net/9/2805/2009/.

Cotton, R. J., Benz, S., Field, P. R., Möhler, O., and Schnaiter, M.: Technical note: a numerical test-bed for detailed ice nucleation studies in the AIDA cloud simulation chamber, Atmos. Chem. Phys., 7, 243-256, 2007, http://www.atmos-chem-phys.net/7/243/2007/.

Curtius, J., Weigel, R., Vossing, H.-J., Wernli, H., Werner, A., Volk, C.-M., Konopka, P., Krebsbach, M., Schiller, C., Roiger, A., Schlager, H., Dreiling, V., and Borrmann, S.: Observations of meteoritic material and implications for aerosol nucleation in the winter Arctic lower stratosphere derived from in-situ particle measurements, Atmos. Chem. Phys., 5, 3053-3069, 2005, http://www.atmos-chem-phys.net/5/3053/2005/.

Cziczo, D. J., Thomson, D. S., and Murphy, D. M.: Ablation, flux, and atmospheric implications of meteors inferred from stratospheric aerosol, Science, 291, 1772-1775, 2001.

Cziczo, D. J., Murphy, D. M., Hudson, P. K. and Thomson, D. S.: Single particle measurements of the chemical composition of cirrus ice residue during CRYSTAL-FACE, J. Geophys. Res.,109, D04201, doi:1029/2003JD004032, 2004.

DeCarlo, P. F., Slowik, J. G., Worsnop, D. R., Davidovits, P., and Jimenez, J. L.: Particle morphology and density characterisation by combined mobility and aerodynamic diameter measurements. Part 1: Theory, Aerosol Sci. Technol., 38, 1185-1205, 2004.

Dymarska, M., Murray, B. J., Sun, L., Eastwood, M., Knopf, D. A., and Bertram, A. K.: Deposition ice nucleation on soot at temperatures relevant for the lower troposphere, J. Geophys. Res., 111, D04204, doi:10.1029/2005JD006627, 2006.

Ebert, V., Teichert, H., Giesemann, C., Saathoff, H., and Schurath, U.: Fibre-coupled in-situ laser absorption spectrometer for the selective detection of water vapour traces down to the ppb-level, Tech. Mess., 72, 23-30, 2005.
Evans, L. F.: Requirements of an ice nucleus, Nature, 206, 822 pp., 1965.

Farlow, N. H., Ferry, G. V., and Blanchard, M. B.: Examination of surfaces exposed to a noctilucent cloud, August 1, 1968, J. Geophys. Res., 75, 6736-6750, 1970.

Field, P. R., Möhler, O., Connolly, P., Krämer, M., Cotton, R., Heymsfield, A. J., Saathoff, H., and Schnaiter, M.: Some ice nucleation characteristics of Asian and Saharan desert dust, Atmos. Chem. Phys., 6, 2991-3006, 2006,

http://www.atmos-chem-phys.net/6/2991/2006/.

Fletcher, N. H.: Size effect in heterogeneous nucleation, J. Chem. Phys., 29, 572-576, 1958.

Fletcher, N. H.: On ice-crystal production by aerosol particles, J. Meteorol., 16, 173-180, 1959.

Fletcher, N. H.: Active sites and ice crystal nucleation, J. Atmos. Sci., 26, 1266-1271, 1969.

Gadsden, M. and Schroder, W.: Noctilucent Clouds, SpringerVerlag, Berlin, Germany, 1989.

Gumbel, J. and Witt, G.: Cluster ions and ice particle nucleation: Positive feedback at the summer mesopause, Geophys. Res. Lett., 29, 1782, doi:10.1029/2002GL015146, 2002.

Gumbel, J. and Megner, L.: Charged meteoric smoke as ice nuclei in the mesosphere: Part 1. - A review of basic concepts, J. Atmos. Sol.-Terr. Phys., 71, 1225-1235, 2009.

Hemenway, C. L., Soberman, R. K., and Witt, G.: Particle sampling from noctilucent clouds, Nature, 199, 269-270, 1963.

Hervig, M. E., Gordley, L. L., Deaver, L. E., Siskind, D. E., Stevens, M. H., Russell III, J. M., Bailey, S. M., Megner, L., and Bardeen, C. G.: First satellite observations of meteoric smoke in the middle atmosphere, Geophys. Res. Lett., 36, L18805, doi:10.1029/2009GL039737, 2009.

Hoppe, U.-P. and Fritts, D. C.: High-resolution measurements of vertical velocity with the European incoherent scatter VHF radar. 1. Motion field characteristics and measurement biases, J. Geophys. Res., 100D(8), 16813-16825, 1995.

Hunten, D. M., Turco, R. P., and Toon, O. B.: Smoke and dust particles of meteoric origin in the mesosphere and stratosphere, J. Atmos. Sci., 37, 1342-1357, 1980.

Kärcher, B., Möhler, O., DeMott, P. J., Pechtl, S., and Yu, F.: Insights into the role of soot aerosols in cirrus cloud formation, Atmos. Chem. Phys., 7, 4203-4227, 2007, http://www.atmos-chem-phys.net/7/4203/2007/.

Keesee, R. G.: Nucleation and particle formation in the upper atmosphere, J. Geophys. Res., 94, 14683-14692, 1989.

Köhler, T. M., Gail, H.-P., and Sedlmayr, E.: MgO dust nucleation in $\mathrm{M}$ stars: calculation of cluster properties and nucleation rates, Astron. Astrophys., 320, 553-567, 1996.

Koop, T., Luo, B., Tsias, A., and Peter, T.: Water activity as the determinant for homogeneous ice nucleation in aqueous solutions, Nature, 406, 611-614, 2000.

Kopcewicz, B. and Kopcewicz, M.: Mössbauer study of ironcontaining atmospheric aerosols, Struct. Chem., 2, 303-312, 1991.

Lanci, L., Kent, D. V., and Biscaye, B. E.: Meteoric smoke concentration in the Vostok ice core estimated from superparamagnetic relaxation and some consequences for estimates of Earth accretion rate, Geophys. Res. Lett., 34, L10803, doi:10.1029/2007GL029811, 2007.

Lübken, F.-J.: Thermal structure of the Arctic summer mesosphere, 
J. Geophys. Res., 104, 9135-9149, 1999.

Magee, N., Moyle. A. M., and Lamb, D.: Experimental determination of the deposition coefficient of small cirrus-like ice crystals near $-50^{\circ} \mathrm{C}$, Geophys. Res. Lett., 33, L17813, doi:10.1029/2006GL026665, 2006.

Megner, L., Siskind, D. E., Rapp, M., and Gumbel, J.: Global and temporal distribution of meteoric smoke: A twodimensional simulation study, J. Geophys. Res., 113, D03202, doi:10.1029/2007JD009054, 2008a.

Megner, L., Gumbel J., Rapp, M., and Siskind, D. E.: Reduced meteoric smoke particle density at the summer pole - Implications for mesospheric ice particle nucleation, Adv. Space Res., 41, 4149, 2008b.

Möhler, O., Stetzer, O., Schaefers, S., Linke, C., Schnaiter, M., Tiede, R., Saathoff, H., Krämer, M., Mangold, A., Budz, P., Zink, P., Schreiner, J., Mauersberger, K., Haag, W., Kärcher, B., and Schurath, U.: Experimental investigation of homogeneous freezing of sulphuric acid particles in the aerosol chamber AIDA, Atmos. Chem. Phys., 3, 211-223, 2003,

http://www.atmos-chem-phys.net/3/211/2003/.

Möhler, O., Büttner, S., Linke, C., Schnaiter, M., Saathoff, H., Stetzer, O., Wagner, R., Krämer, M., Mangold, A., Ebert, V., and Schurath, U.: Effect of sulfuric acid coating on heterogeneous ice nucleation by soot aerosol particles, J. Geophys. Res., 110, D11210, doi:11210.11029/12004JD005169, 2005.

Möhler, O., Field, P. R., Connolly, P., Benz, S., Saathoff, H., Schnaiter, M., Wagner, R., Cotton, R., Krämer, M., Mangold, A., and Heymsfield, A. J.: Efficiency of the deposition mode ice nucleation on mineral dust particles, Atmos. Chem. Phys., 6, 30073021, 2006, http://www.atmos-chem-phys.net/6/3007/2006/.

Möhler, O., Benz, S., Saathoff, H., Schnaiter, M., Wagner, R., Schneider, J., Walter, S., Ebert, V., and Wagner, S.: The effect of organic coating on the heterogeneous ice nucleation efficiency of mineral dust aerosols, Environ. Res. Lett., 3, 1-8, 2008.

Mossop, S. C.: Stratospheric particles at $20 \mathrm{~km}$, Nature, 199, 325326, 1963.

Murphy, D. M., Thomson, D. S., and Mahoney, M. J.: In situ measurements of organics, meteoritic material, mercury, and other elements in aerosols at 5 to 19 kilometers, Science, 282, 16641669, 1998.

Murphy, D. M. and Koop, T.: Review of the vapour pressures of ice and supercooled water for atmospheric applications, Q. J. Roy. Meteorol. Soc., 131, 1539-1565, 2005.

Murray, B. J., Knopf, D. A., and Bertram, A. K.: The formation of cubic ice under conditions relevant to the Earth's atmosphere, Nature, 434, 202-205, 2005.

Murray, B. J. and Jensen, E. J.: Homogeneous nucleation of amorphous solid water particles in the upper mesosphere, J. Atmos. Sol.-Terr. Phys., 72, 51-61, 2010.

Murray, B. J., Bull, S., Wilson, T. W., and Wills, R.: Heterogeneous ice nucleation by illite clay under conditions relevant for the Earth's atmosphere, in preparation, 2010.

Park, G.-S., Shindo, D., Waseda, Y., and Sugimoto, T.: Internal structure analysis of monodispersed pseudocubic hematite particles by electron microscopy, J. Colloid Interf. Sci., 177, 198-207, 1996.

Plane, J. M. C. and Helmer, M.: Laboratory study of the reactions $\mathrm{Mg}+\mathrm{O}_{3}$ and $\mathrm{MgO}+\mathrm{O}_{3}$ : Implications for the chemistry of magnesium in the upper atmosphere, Faraday Discuss., 100, 411-
430, 1995.

Plane, J. M. C.: The role of sodium bicarbonate in the nucleation of noctilucent clouds, Ann. Geophys., 18, 807-814, 2000, http://www.ann-geophys.net/18/807/2000/.

Pruppacher, H. R. and Klett, J. D.: Microphysics of Clouds and Precipitation, Kluwer Academic Publishers, Dordrecht, The Netherlands, 1997.

Rapp, M. and Lübken, F.-J.: Polar mesosphere summer echoes (PMSE): review of observations and current understanding, Atmos. Chem. Phys., 4, 2601-2633, 2004, http://www.atmos-chem-phys.net/4/2601/2004/.

Rapp, M., Hedin, J., Strelnikova, I., Friedrich, M., Gumbel, J., and Lübken, F.-J.: Observations of positively charged nanoparticles in the nighttime polar mesosphere, Geophys. Res. Lett., 32, L23821, doi:10.1029/2005GL024676, 2005.

Rapp, M. and Thomas, G. E.: Modeling the microphysics of mesospheric ice particles: assessment of current capabilities and basic sensitivities, J. Atmos. Sol.-Terr. Phys., 68, 715-744, 2006.

Rapp, M.: Charging of mesospheric aerosol particles: the role of photodetachment and photoionization from meteoric smoke and ice particles, Ann. Geophys., 27, 2417-2422, 2009, http://www.ann-geophys.net/27/2417/2009/.

Reid, G. C.: The nucleation and growth of ice particles in the upper mesosphere, Adv. Space Res., 20, 1285-1291, 1997.

Roddy, A. F.: Role of meteoric particles in noctilucent clouds, Irish Astron. J., 16, 194-202, 1984.

Rosinski, J. and Snow, R. H.: Secondary particulate matter from meteor vapors, J. Meteorol., 18, 736-745, 1961.

Saunders, R. W. and Plane, J. M. C.: A laboratory study of meteor smoke analogues; composition, optical properties and growth kinetics, J. Atmos. Sol.-Terr. Phys., 68, 2182-2202, 2006.

Seele, C. and Hartogh, P.: Water vapour of the polar middle atmosphere: annual variation and summer mesosphere conditions as observed by ground-based microwave spectroscopy, Geophys. Res. Lett., 26, 1517-1520, 1999.

Seifert, M., Tiede, R., Schnaiter, M., Linke, C., Möhler, O., Schurath, U., and Ström, J.: Operation and performance of a differential mobility particle sizer and a TSI 3010 condensation particle counter at stratospheric temperatures and pressures, J. Aero. Sci., 35, 981-993, 2004.

Shilling, J. E., Tolbert, M. A., Toon, O. B., Jensen, E. J., Murray, B. J., and Bertram, A. K.: Measurements of the vapour pressure of cubic ice and their implications for atmospheric ice clouds, Geophys. Res. Lett., 33, L17801, doi:10.1029/2006GL026671, 2006.

Strelnikova, I., Rapp, M., Raizada, S., and Sulzer, M.: Meteor smoke particle properties derived from Arecibo incoherent scatter radar observations, Geophys. Res. Lett., 34, L15815, doi:10.1029/2007GL030635, 2007.

Sugimoto, T. and Sakata, K.: Preparation of monodisperse pseudocubic $\alpha-\mathrm{Fe}_{2} \mathrm{O}_{3}$ particles from condensed ferric hydroxide gel, J. Colloid Interf. Sci., 152, 587-590, 1992.

Trainer, M. G., Toon, O. B., and Tolbert, M. A.: Measurements of depositional ice nucleation on insoluble substrates at low temperatures: Implications for Earth and Mars, J. Phys. Chem. C, 113, 2036-2040, 2009.

Turco, R. P., Toon, R. B., Hamill, P., and Whitten, R. C.: Effects of meteoric debris on stratospheric aerosols and gases, J. Geophys. Res., 86, 1113-1128, 1981. 
von Zahn, U. and Meyer, W.: Mesopause temperatures in polar summer, J. Geophys. Res., 94, 14647-14651, 1989.

von Cossart, G., Fiedler, J., and von Zahn, U.: Size distributions of NLC particles as determined from 3-color observations of NLC by ground-based lidar, Geophys. Res. Lett., 26, 1513-1516, 1999.

Vondrak, T., Plane, J. M. C., Broadley, S., and Janches, D.: A chemical model of meteoric ablation, Atmos. Chem. Phys., 8, 70157031, 2008, http://www.atmos-chem-phys.net/8/7015/2008/.

Wagner, R., Benz, S., Möhler, O., Saathoff, H., and Schurath, U.: Probing ice clouds by broadband mid-infrared extinction spectroscopy: Case studies from ice nucleation experiments in the AIDA aerosol and cloud chamber, Atmos. Chem. Phys., 6, 47754800, 2006, http://www.atmos-chem-phys.net/6/4775/2006/.
Wagner, R., Benz, S., Möhler, O., Saathoff, H., Schnaiter, M., and Leisner, T.: Influence of particle aspect ratio on the mid infrared extinction spectra of wavelength-sized ice crystals, J. Phys. Chem. A, 111, 13003-13022, 2007.

Whalley, E.: Cubic ice in nature, J. Phys. Chem., 87, 4174-4179, 1983.

Zasetsky, A. Y., Petelina, S. V., and Svishchev, I. M.: Thermodynamics of homogeneous nucleation of ice particles in the polar summer mesosphere, Atmos. Chem. Phys., 9, 965-971, 2009, http://www.atmos-chem-phys.net/9/965/2009/.

Zondlo, M. A., Hudson, P. K., Prenni, A. J. and Tolbert, M. A.: Chemistry and microphysics of polar stratospheric clouds and cirrus clouds, Annu. Rev. Phys. Chem., 51, 473-499, 2000. 